\title{
Experimental and numerical study on the evaporation rates of liquid fuels using a controlled atmosphere cone calorimeter
}

\author{
Tarek Beji ${ }^{\mathrm{a}^{*}}$, Olivier Helson ${ }^{\mathrm{b}}$, Thomas Rogaume ${ }^{\mathrm{b}}$, Jocelyn Luche ${ }^{\mathrm{b}}$ \\ ${ }^{a}$ Ghent University, Department of Structural Engineering, Belgium, Tarek.Beji@UGent.be \\ b Institut Pprime, UPR 3346 CNRS, Université de Poitiers, ISAE-ENSMA, France, \\ thomas.rogaume@univ-poitiers.fr
}

*Corresponding author

\begin{abstract}
:
The work described in this paper presents a set of experimental tests carried out in a Controlled Atmosphere Cone Calorimeter (CACC) in order to study the evaporation rate of a $250 \mathrm{ml}$-'batch' of $n$-heptane and methanol poured into an insulated $0.10 \times 0.10 \times 0.04 \mathrm{~m}^{3}$ steel pan and exposed to two 'nominal' irradiation levels of 25 and $50 \mathrm{~kW} / \mathrm{m}^{2}$. A low oxygen concentration is imposed during the CACC tests. The intent is to provide experimental data for the assessment and validation of the numerical modelling of liquid heat-up and evaporation in pool fires, without the need to model combustion and the subsequent associated complex phenomena. The analysis of the mass loss rate profiles shows that the evaporation rate of n-heptane increases with time due to the preheating of the liquid, whereas for methanol, a quasi-steady-state is reached. This is due to differences in specific heat, boiling point and latent heat of vaporization. Numerical simulations of the liquid phase using the Fire Dynamics Simulator (version 6.7.0) point out the importance to account for increased heat transfer due to the convective motion of the liquid by increasing the thermal conductivity of the liquid by 10 to 20 times. Other limitations and uncertainties in the modeling are also highlighted.
\end{abstract}

Keywords: evaporation; liquid pool fires; Controlled Atmosphere Cone Calorimeter (CACC); numerical modelling 


\section{Introduction}

Pool fires are a potential source of hazard in a number of industrial applications such as the nuclear or the oil industry. Predictive simulation tools are thus being developed in order to understand the fire dynamics and mitigate the adverse effects of such types of fires. Substantial advances have been achieved at the level of the gas phase in the prediction of the flame structure and, to some extent, the subsequent thermal radiation. On the contrary, little experimental and numerical modelling research is undertaken at the level of (i) the liquid - gas interface (where evaporation occurs), and (ii) the liquid phase being heated up. This is mainly due to the availability of 'simple' engineering approaches that allow to have an estimate of the liquid mass loss rate (MLR) and use it as a boundary condition for the treatment of the gas phase. The most commonly used correlation in this regard is the semi-empirical expression of Babrauskas [1] which requires, as input, the pool diameter, the (maximum) limiting burning rate and the extinction coefficient, the latter two being fuel-dependent parameters that are determined experimentally for a number of liquid fuels. In enclosure fires, the same expression could be used along with the correlation of Peatross and Beyler [2] and which accounts for the effect of under-ventilated conditions (i.e., low oxygen levels). The main drawback of the above engineering approach is that the mass transfer process (i.e., liquid evaporation) is fully decoupled from heat transfer phenomena, which can be detrimental in terms of accuracy under some specific conditions. A more 'elaborate' approach consists of considering the liquid MLR being mainly driven by the heat flux at the liquid surface, assuming that the latter has reached the boiling point (e.g., [3, 4]). The main disadvantage here is that the latter assumption may be valid for a fully developed fire (as stated in [3]) but not for an under-ventilated fire, with a 'weak' flame and a reduced heat flux at the surface. The numerical study performed in [5] shows that when the heat flux at the surface is not sufficiently high, the liquid evaporation process is mainly driven by the liquid vapor concentration gradients rather than the heat flux at the surface.

Based on the above, a more 'fundamental' approach is required in order to improve the current predictive capabilities of the numerical modelling of liquid pool fires. In such approach, liquid heat-up and evaporation must be modelled accurately without substantially increasing the computational requirements for 'real-life' applications. To the best of our knowledge, the most recent and comprehensive work on predictive CFD simulations of liquid pool fires has been 
undertaken by Sikanen and Hostikka [6], where evaporation is modelled using the 'film theory' and convection within the liquid, due to in-depth radiation, is modeled using the 'effective thermal conductivity concept'. The modelling proposed in [6] has been assessed against (1) available engineering correlations (e.g., [1]), (2) a $0.81 \times 0.70 \mathrm{~m}^{2}$ ethanol pool fire case from Victoria University [7], and (3) the evaporation of water under a $50 \mathrm{~kW} / \mathrm{m}^{2}$ external heat flux in the ASTM E2058 fire propagation apparatus [8]. The results obtained were very encouraging. Nevertheless, several numerical results required further investigation among which (1) a too fast rise in the evaporation rate (and thus, the burning rate) in comparison with the experimental data, and (2) some difficulties to ensure a 'physically plausible' thermal structure within the liquid. This is not surprising, given the level of complexity which stems from the interaction between combustion, thermal radiation, convection, evaporation and heat transfer within the liquid.

In order to 'make significant and systematic progress in fire modelling' (as advocated in the IAFSS Working Group on Measurement and Computation of Fire Phenomena, MaCFP, see https://iafss.org/macfp/), and more specifically pool fire modelling, a fundamental approach is required where the sub-models of interest are validated using a 'step-wise' approach, starting from 'simple' 'unit tests' before considering benchmark cases, subsystems and, at a later stage, 'reallife' applications. Following the above, a numerical study has been conducted in [5] on liquid evaporation modelling using the 'film theory' for a thermally thin liquid layer, without combustion and under a constant heat flux. This allowed to focus only on evaporation at the liquid - gas interface and highlight (amongst other aspects) the importance of the choice of the correlation for the Sherwood number (which is directly proportional to the evaporation rate). In another theoretical study [9-10], the focus was put on heat transfer within the liquid and more specifically, modelling the effect of in-depth radiation. These studies $[5,9,10]$ require comprehensive and welldocumented experimental data for assessment and validation. Similarly, to the numerical approach, it is desirable to develop experimental programs aiming to decouple, as much as possible, several aspects of the physics in order to validate separately the corresponding submodels.

It is with this intent that the experimental campaign presented in this paper has been developed. More precisely, the goal is to provide experimental data for the validation of heat-up and 
evaporation modelling of several liquid fuels in 'controlled' conditions, without the need to consider combustion and the subsequent complex phenomena. This is mainly inspired from one test case examined in [6] which is the evaporation of water under a $50 \mathrm{~kW} / \mathrm{m}^{2}$ external heat flux in the ASTM E2058 fire propagation apparatus [8]. The main constraint for liquids other than water is the need to prevent ignition, by imposing a low oxygen concentration in the surrounding environment. This is a possibility offered by the Controlled Atmosphere Cone Calorimeter (CACC) which has been mainly designed to examine the thermal degradation of solid test specimens at several oxygen levels; its use for liquid fuels is very scarce. Therefore, the first objective of this work is to develop an experimental framework (e.g., instrumentation, experimental protocol, methodology for the analysis of the results) that supports the modelling of liquid heat-up and evaporation. The second objective is to undertake a detailed assessment of the Fire Dynamics Simulator (FDS 6.7.0) [11], focusing on the liquid phase, in order to identify modelling aspects that need to be improved in the future.

In the remainder of the paper, a description of the experimental set-up and test cases is provided,

followed by a display and a detailed analysis of the experimental results. The experimental study is followed by a detailed numerical study with an extensive sensitivity analysis on several modelling details.

\section{Experimental set-up, test cases and results}

\subsection{The Controlled Atmosphere Cone Calorimeter (CACC)}

The Controlled Atmosphere Cone Calorimeter (CACC) (see Figs. 1 and 2) is, in many aspects, similar to the standard Cone Calorimeter (CC). It is composed of a conical radiant heater set at a specific temperature, which corresponds to a 'desired' irradiation level onto the surface of a sample. The sample holder stands on a load cell that allows to measure the mass loss of the specimen as function of time. Pyrolysis and combustion products are collected within an exhaust system (composed of a hood and a duct work) and then analyzed to measure, for instance, the Heat Release Rate (HRR). A schematic representation of the CACC used during the present study is presented in Fig. 2. 

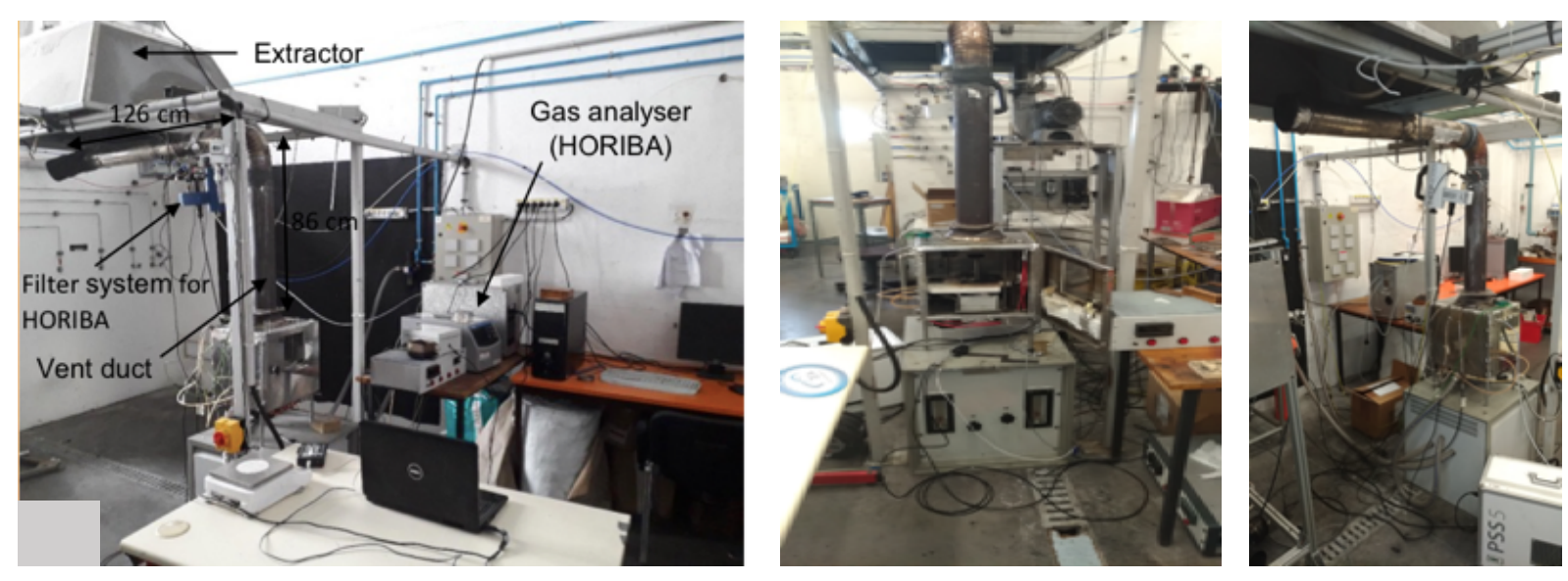

Figure 1 - Pictures of the experimental set-up.
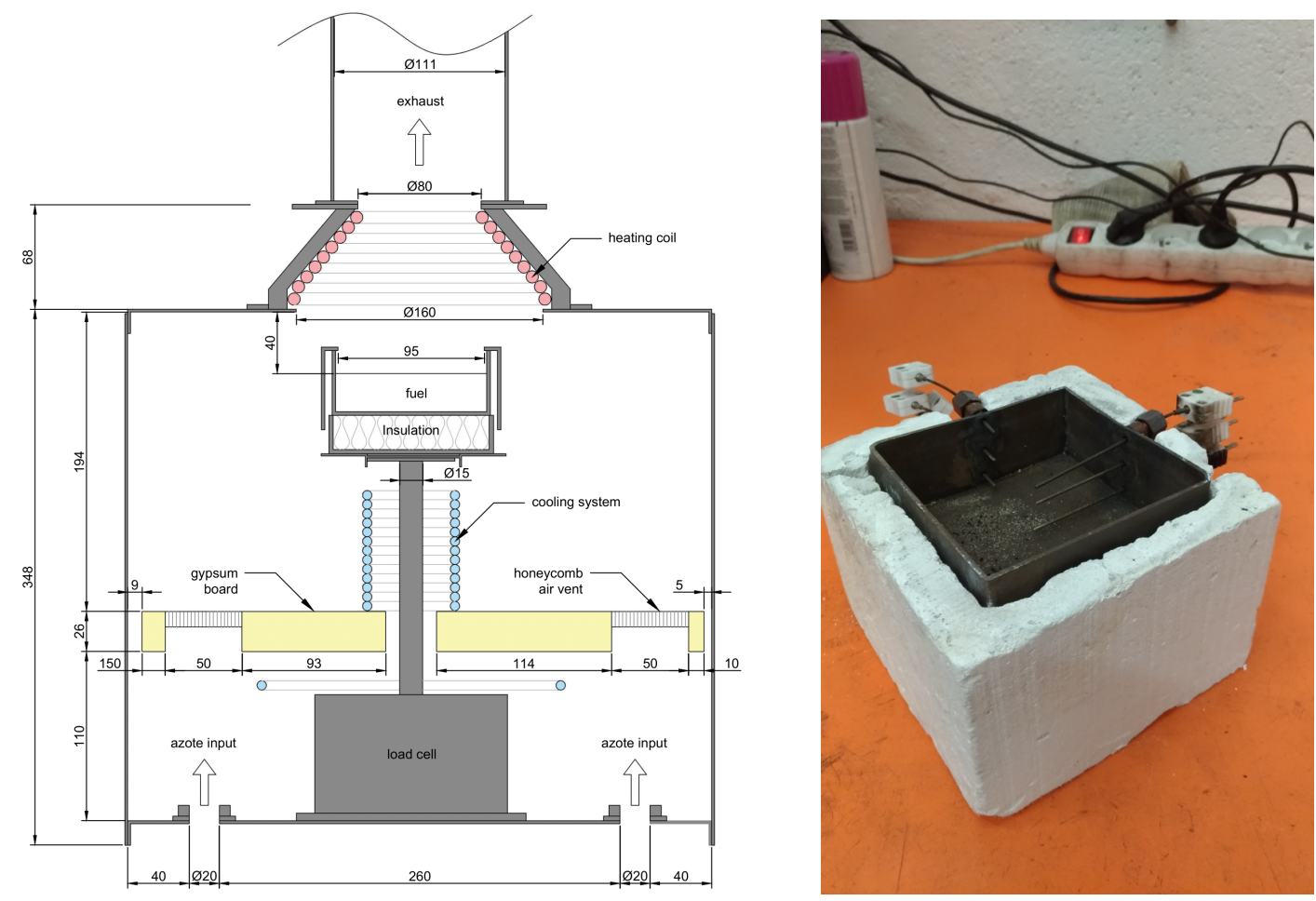

Figure 2 - Schematic diagram of the Controlled Atmosphere Cone Calorimeter (CACC) (left). A photo of the pan and the thermocouples (right). 
The CACC has been designed with the intent to emulate under-ventilated conditions that might occur in an enclosure fire and study the subsequent burning behavior of several types of materials in such conditions [12]. The main modifications that were required to convert the CC into a CACC were the installation of a nitrogen/air delivery and control system, the sealing of the combustion chamber and the setting a blow-through system with a fan and a feedback controller. More details are provided in [12]. Most of the experimental studies using CACC and reported in the literature are focused on the degradation of solid fuels, e.g., PMMA [13], with the intent to obtain kinetic parameters used in pyrolysis models. A review of CACC studies is provided in [14]. The 'interpretation' of CACC results is discussed in [13]. Furthermore, an estimation of uncertainties and errors in CACC measurements, which are important points in this work, is addressed in [15]. During the experiments carried out in this work, nitrogen was inserted through two $19.5 \pm 0.5-\mathrm{mm}$ inlet diameter orifices (see Fig. 2) with a volume flow rate of $\mathrm{V}_{\mathrm{N} 2}=145 \pm 5 \mathrm{liter} / \mathrm{min}$. The CACC enclosure was not completely sealed (due to the need to connect instrumentation wires to the outside). Nevertheless, for each test, the average oxygen concentration did not exceed $5 \%$. The gas analyzer HORIBA PG250 used in this study measures the oxygen concentration by electrochemical Zirconia method. In order to minimize the device drift, a gypsum board is positioned above the load cell (see Fig. 3) and a water-cooling channel moderates its increase in temperature. The gypsum board includes three-honeycomb rectangular air vents of $50 \mathrm{~mm} \times 100 \mathrm{~mm}$ to ensure well-mixed conditions.

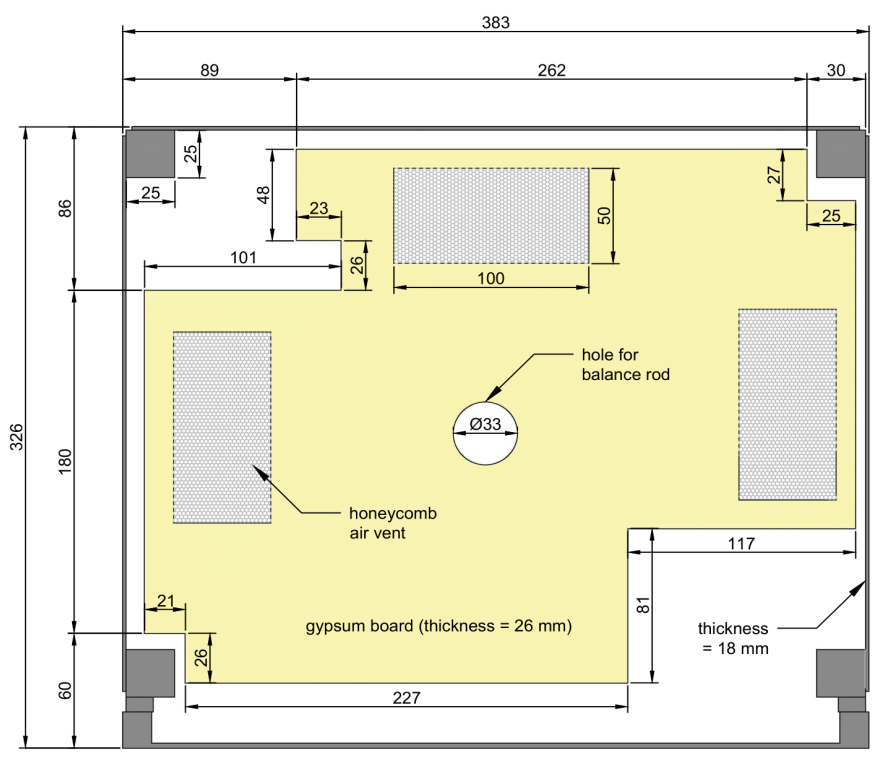

Figure 3 - Schematic diagram of the gypsum plate positioned in the chamber. 


\subsection{The liquid container and the irradiation levels}

In this study, the liquid container (see Fig. 2, right) is a square-shaped pan with inner dimensions of $98.0 \pm 2.0 \mathrm{~mm}$ and a depth of $40.0 \pm 2.0 \mathrm{~mm}$. The pan is made of stainless steel with a thickness of $2.1 \pm 0.2 \mathrm{~mm}$. It is insulated from the sides and at the bottom with calcium silicate (see Fig. 2, right). The 'side insulation' is about $18 \mathrm{~mm}$-thick and the 'bottom insulation' is about $57 \mathrm{~mm}$ thick. The insulated pan is positioned on a weighing system with a resolution of $0.01 \mathrm{~g}$. At the start of each experiment, $250 \mathrm{ml}$ of a liquid fuel was poured into the tank, leaving a lip height of approximately $15 \mathrm{~mm}$.

The fuel temperature (initially between $15^{\circ} \mathrm{C}$ and $19^{\circ} \mathrm{C}$ ) was measured by 4 thermocouples inserted through the side of the pan in. Two thermocouples are positioned at the center at respectively 6 and $19 \mathrm{~mm}$ from the bottom of the pan. Two other thermocouples are positioned at the same heights but at $1 \mathrm{~cm}$ from the side of the pan (and not in the center). Above the liquid, at about $33 \mathrm{~mm}$ from the bottom of the pan (i.e., about $8 \mathrm{~mm}$ above the initial liquid surface), two thermocouples were used to measure the gas temperature at the center and on the side (near the burner wall).

Two 'nominal' irradiation levels were considered: $25 \mathrm{~kW} / \mathrm{m}^{2}$ and $50 \mathrm{~kW} / \mathrm{m}^{2}$. These values were calibrated at the start of each test at a position that corresponds to the center of the liquid surface.

\subsection{Fuel selection and list of test cases}

Methanol and n-heptane were mainly selected based on (1) their latent heat of vaporization, $L_{v}$, and (2) the sensible heat required to bring the liquid fuel from the initial ambient temperature to the boiling point, $T_{b}$ (see Table 1). The sensible heat is expressed as $c_{p}\left(T_{b}-T_{a}\right)$, assuming that the specific heat, $c_{p}$, does not vary substantially with temperature. The substantial difference in both parameters (i.e., 315 to $1099 \mathrm{~kJ} / \mathrm{kg}$ for the latent heat of vaporization and 77 to $176 \mathrm{~kJ} / \mathrm{kg}$ for the sensible heat) and even more so their ratio, i.e., $c_{p}\left(T_{b}-T_{a}\right) / L_{v}$, ranging from 0.1 to 0.6 , leads to substantial differences in the heat-up and evaporation processes, as it will be discussed later in the paper. 
Table 1 - Liquid properties that are useful and relevant for the analysis and modelling of heat up and evaporation [6].

\begin{tabular}{|l|l|l|l|l|l|l|l|l|}
\hline Liquid & Formula & Purity & $\begin{array}{l}\mathrm{MW} \\
(\mathrm{g} / \mathrm{mol})\end{array}$ & $\begin{array}{l}\rho \\
\left(\mathrm{kg} / \mathrm{m}^{3}\right)\end{array}$ & $\begin{array}{l}k \\
(\mathrm{~W} / \mathrm{m} . \mathrm{K})\end{array}$ & $\begin{array}{l}c_{p} \\
(\mathrm{~kJ} / \mathrm{kg} \cdot \mathrm{K})\end{array}$ & $\begin{array}{l}L_{v} \\
(\mathrm{~kJ} / \mathrm{kg})\end{array}$ & $\begin{array}{l}T_{b} \\
\left({ }^{\circ} \mathrm{C}\right)\end{array}$ \\
\hline Methanol & $\mathrm{CH} \mathrm{H}_{3} \mathrm{OH}$ & $\geq 99.9 \%$ & 32 & $\begin{array}{l}791 @ \\
25^{\circ} \mathrm{C}\end{array}$ & 0.20 & 2.48 & 1099 & 64.8 \\
\hline $\begin{array}{l}\mathrm{n}- \\
\text { Heptane }\end{array}$ & $\mathrm{n}-\mathrm{C}_{7} \mathrm{H}_{16}$ & $\geq 99 \%$ & 100 & $\begin{array}{l}684 @ \\
25^{\circ} \mathrm{C}\end{array}$ & 0.14 & 2.24 & 315 & 98.5 \\
\hline
\end{tabular}

Table 2 - List of the experimental test cases.

\begin{tabular}{|c|c|c|c|c|c|}
\hline Test case ID & Liquid & $\begin{array}{c}\text { Nominal } \\
\text { radiative } \\
\text { heat flux } \\
\left(\mathrm{kW} \cdot \mathrm{m}^{-2}\right)\end{array}$ & $\begin{array}{c}\text { Gas } \\
\text { extraction } \\
\text { in } \\
\text { operation }\end{array}$ & $\begin{array}{c}\text { Insulated } \\
\text { sample } \\
\text { holder }\end{array}$ & $\begin{array}{c}\text { Average gas } \\
\text { temperature in the } \\
\text { extraction duct } \\
\left({ }^{\circ} \mathrm{C}\right)\end{array}$ \\
\hline H25\#1 & n-Heptane & 25 & Yes & Yes & $126 \pm 8$ \\
\hline H25\#2 & n-Heptane & 25 & Yes & Yes & $126 \pm 6$ \\
\hline H25\#3 & n-Heptane & 25 & Yes & Yes & NA \\
\hline H25\#4 & n-Heptane & 25 & No & Yes & $125 \pm 7$ \\
\hline H25\#5 & n-Heptane & 25 & Yes & No & $116 \pm 14$ \\
\hline H50\#1 & n-Heptane & 50 & Yes & Yes & $164 \pm 13$ \\
\hline H50\#2 & n-Heptane & 50 & Yes & Yes & $168 \pm 11$ \\
\hline H50\#3 & n-Heptane & 50 & Yes & Yes & $174 \pm 7$ \\
\hline M25\#1 & Methanol & 25 & Yes & Yes & $122 \pm 8$ \\
\hline M25\#2 & Methanol & 25 & Yes & Yes & $119 \pm 9$ \\
\hline M50\#1 & Methanol & 50 & Yes & Yes & $162 \pm 30$ \\
\hline M50\#2 & Methanol & 50 & Yes & Yes & $170 \pm 14$ \\
\hline
\end{tabular}

* In fact, a plate in 'vermiculite' has been positioned between the pan and the mass balance, in order to avoid any damage to the mass balance due to excessive heat. 
Table 2 displays the list of experimental tests undertaken in this work. The nomenclature of the tests is as follows. The letter is the first letter of the liquid's name, the first number indicates the 'nominal' irradiation level, and the second number is indicative of the repeatability of the test. In addition to the change in fuel and 'nominal' irradiation level, the effect of the extraction as well as the effect of the insulation have been examined in respectively tests $\mathrm{H} 25 \# 4$ and H25\#5. Table 2 presents also the recorded average gas temperature during the tests in the extraction ducts.

\subsection{Experimental protocol}

The experimental protocol is as follows:

1- Adjust the height of the thermo-balance (distance of $25 \mathrm{~mm}$ between the top of the sample holder and the radiative spiral. So, the distance between the top of liquid at the beginning of the test and the radiative spiral is of $40 \mathrm{~mm}$ ).

2- Tare with empty sample holder.

3- Calibrate the radiative heat flux at the initial liquid height position (in the center) with a Schmidt Boelter fluxmeter.

4- Put on the fan in the extraction duct.

5- Close the door and inject nitrogen. Monitor the concentration until a stabilized value is obtained.

6- Put the liquid in the container and then in the chamber. Start the baseline and wait until the nitrogen and oxygen concentrations are stabilized again. For all tests, the measured steady-state oxygen concentration is typically below $2 \%$.

7- Make sure that all the instrumentation is OK (temperatures, gas, mass measurements).

8- Start the test by opening the damper (without ignitor). Simultaneously, start data acquisition (mass loss, gas analysis, temperature).

9- End of the test when the mass is zero.

10- Stop the supply of nitrogen and close the damper.

11- Put the supply of air (this is important for safety reasons by avoiding the accumulation of flammable hot vapor at the end of the test).

12- Open the door and take out the sample holder.

13- Stop the extraction fan.

14- Cool down the sample holder with water and compressed air for the next test. 


\subsection{Experimental results}

\subsubsection{Evaporation rates}

Figure 4 shows the Mass Loss Rate Per Unit Area (MLRPUA) or evaporation rate profiles averaged over every $15 \mathrm{~s}$ for the 12 tests listed in Table 2 (the mass measurements are actually recorded every $1 \mathrm{~s})$.

An overall good repeatability is shown in Fig. 4. It is noted though that there are variations in the time to full evaporation (i.e., complete consumption of the liquid fuel). This can be mainly attributed to some spillage of the liquid before positioning the pan in the cone calorimeter enclosure. Such manipulation was indeed quite difficult given the small space in which the pan should be inserted. Some spillage inside the enclosure may have caused the 'residual' evaporation rates recorded for example at the end of tests $\mathrm{H} 25 \# 1$ and $\mathrm{H} 50 \# 1$.

The results for $\mathrm{H} 25 \# 4$ and $\mathrm{H} 25 \# 5$ are not significantly different from the results of tests $\mathrm{H} 25 \# 1$ to H25\#3. Therefore, it can be concluded that the effects of respectively the extraction and the calcium silicate insulation are not significant and can be neglected.
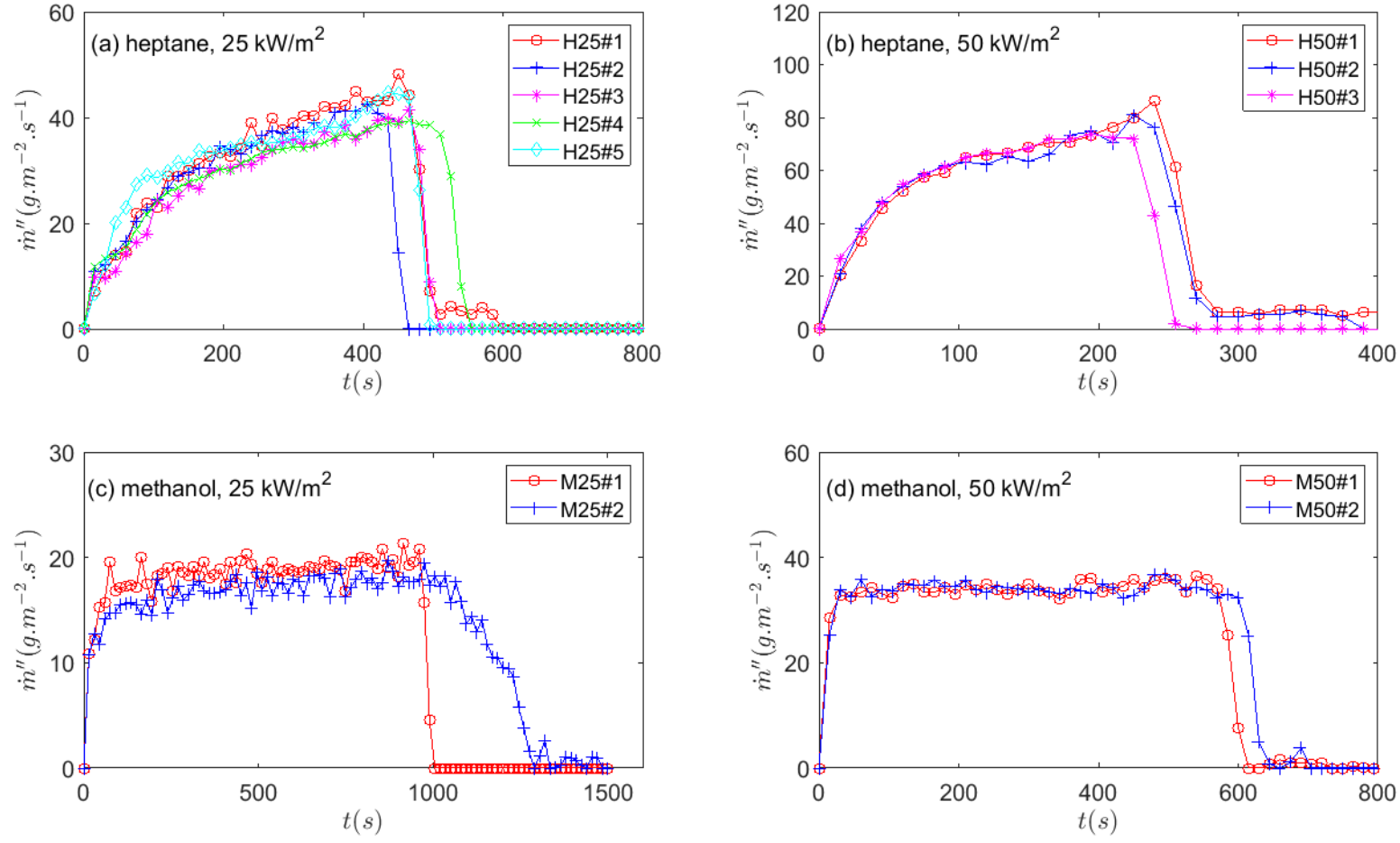

Figure 4-Mass loss (evaporation) rates per unit area. 
The above recorded data for the evaporation rates is compared to available data in the literature on the burning rates in flaming conditions for a range of burner diameters of interest in this work. For example, in [16] the burning rate of a $5 \mathrm{~cm}$-diameter heptane (resp. methanol) is between 15 and $25 \mathrm{~g} \cdot \mathrm{m}^{-2} \cdot \mathrm{s}^{-1}$ (resp. about $15 \mathrm{~g} \cdot \mathrm{m}^{-2} \cdot \mathrm{s}^{-1}$ ). The steady-state burning rate correlation in [1] for a $20 \mathrm{~cm}-$ diameter (the lower applicability limit of the correlation) gives $20 \mathrm{~g} \cdot \mathrm{m}^{-2} \cdot \mathrm{s}^{-1}$ for heptane and $17 \mathrm{~g} . \mathrm{m}^{-}$ ${ }^{2} \cdot \mathrm{s}^{-1}$ for methanol. These burning rates (obtained from the literature) show that a heat flux of 25 $\mathrm{kW} \cdot \mathrm{m}^{-2}$ is more 'indicative' of the actual heat flux (exerted on the liquid surface) in flaming conditions than a heat flux of $50 \mathrm{~kW} \cdot \mathrm{m}^{-2}$.

It is interesting to note that, as opposed to methanol, there is no quasi-steady state for the n-heptane tests. This aspect has been studied in [16] for burning pool fires and is essentially explained by the thermal structure of the liquid, see Fig. 5.

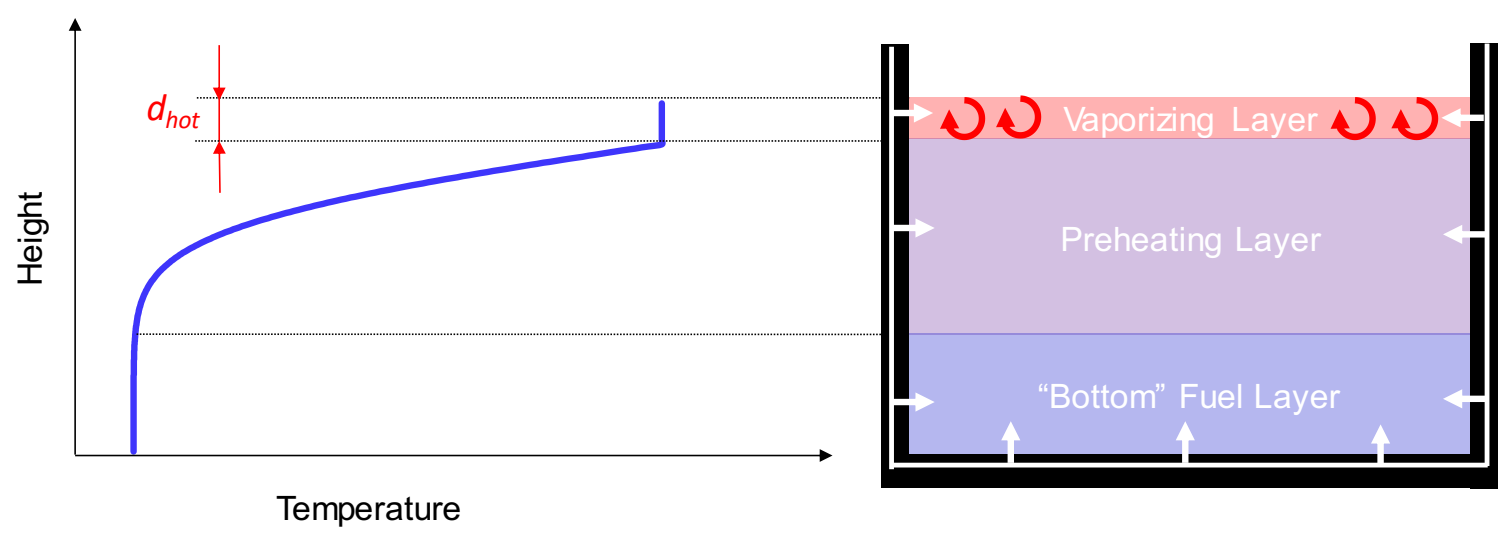

Figure 5 - Thermal structure within the liquid in the case of a pool fire. Left figure: temperature profile across the liquid height. Right figure: layered structure as described in [16]; the red arrows represent the convective motion due to in-depth radiation and the white arrows represent heat transfer from the pool wall to the liquid.

In Fig. 5, at the early stages of the evaporation process, there are three distinct regions in the liquid (as described in [16]): (1) the vaporizing (boiling) layer characterized by a uniform temperature, (2) the preheating layer characterized by a temperature gradient, and (3) a bottom cold layer where there is no temperature gradient. Furthermore, detailed experimental data for a $9 \mathrm{~cm}$ - diameter steady-state methanol pool fire clearly highlights the presence of an isothermal vaporizing layer on top of a preheating layer [17-19]. 
After the initial heating-up stage where the evaporation process is mainly driven by liquid vapor concentration gradients, a quasi-steady state stage starts to be established where the liquid surface temperature reaches a saturation temperature (near the boiling point or lower, depending on the heat flux at the surface).

During this quasi-steady stage, the evaporation process is driven by the net heat flux received at the liquid surface, $\dot{q}_{n e t}^{\prime \prime}$ :

$$
\dot{m}_{\text {min }}^{\prime \prime}=\frac{\dot{q}_{n e t}^{\prime \prime}}{L_{v}+c_{p}\left(T_{b}-T_{\ell}\right)}
$$

where $T_{\ell}$ is the liquid temperature in the preheating layer.

In fact, steady state evaporation (or burning for a reactive case) is not reached because the heat flux (at the liquid surface) heats up the liquid in the preheating layer from a temperature slightly above the initial ambient temperature until it approaches (and reaches) the saturation temperature. As the liquid temperature in the 'preheating layer' is continuously rising (the bottom of the pan is insulated), a thermally thin layer remains toward the end of the test, yielding a MLRPUA that is expressed as:

$$
\dot{m}_{\max }^{\prime \prime}=\frac{\dot{q}_{n e t}^{\prime \prime}}{L_{v}}
$$

By dividing Eq. (2) by Eq. (1) (as in [16]), one obtains a factor that is mainly dependent on the fuel properties (more specifically, the specific heat, the boiling temperature and the latent heat of vaporization) and the initial liquid temperature:

$\gamma=\frac{\dot{m}^{\prime \prime}{ }_{\text {max }}}{\dot{m}_{\text {min }}}=1+\frac{c_{p}\left(T_{b}-T_{\ell}\right)}{L_{v}}$

The factor, $\gamma$, expresses the level of increase in the evaporation rate as the liquid layer becomes thermally thin (just before full consumption of the liquid). For a liquid temperature $T_{\ell}=20^{\circ} \mathrm{C}$, the theoretical values of $\gamma$ for $\mathrm{n}$-heptane and methanol are respectively $\gamma_{\mathrm{th} \text {,heptane }}=1.6 \gamma_{\mathrm{th} \text {,methanol }}=1.1$. These values are in a good qualitative agreement with the experimental profiles displayed in Fig. 4. It is difficult though (especially for n-heptane) to estimate $\gamma$ with accuracy based on the experimental data because there is no clear quasi-steady stage where the evaporation rate is governed by Eq. (1) and where the bottom liquid temperature remains near ambient. 
It is important to recall that the above analysis (using Eqs. (1) and (2)) is only relevant if the incident heat flux is sufficiently high so that the evaporation rate of the liquid becomes mainly driven by heat transfer [5]. Otherwise, it might not hold if the evaporation process is driven by concentration gradients. The above analysis has been first been presented in [16] for liquid pool fires. It is presented here for evaporating liquids (without combustion).

By considering Eq. (2) and taking $\dot{q}_{n e t}^{\prime}$ as the nominal radiative heat flux set up in the experiments, i.e., $\dot{q}_{n e t}^{\prime \prime}=\dot{q}_{r a d}^{\prime \prime}=25 \mathrm{~kW} / \mathrm{m}^{2}$ and $\dot{q}_{n e t}^{\prime \prime}=\dot{q}_{r a d}^{\prime \prime}=50 \mathrm{~kW} / \mathrm{m}^{2}$, one can have an estimate of the peak evaporation rates for each of the test cases examined in this work. Surprisingly, as shown in Table 3 , there are substantial deviations of about 9 to $46 \%$ with the experimental measurements of the mass loss rates per unit area.

Table 3 - A comparison between the experimentally measured and the estimated values of the peak evaporation rates.

\begin{tabular}{|l|l|l|l|l|}
\hline \multirow{2}{*}{ Liquid } & $\begin{array}{l}\text { Nominal radiative } \\
\text { heat flux } \\
\left(\mathrm{kW} \cdot \mathrm{m}^{-2}\right)\end{array}$ & $\begin{array}{l}\dot{m}_{\max }^{\prime \prime}-\text { Exp. data } \\
\left(\mathrm{g} \cdot \mathrm{m}^{-2} \cdot \mathrm{s}\right)\end{array}$ & $\begin{array}{l}\dot{m}_{\max }^{\prime \prime}-\text { Eq. (2) } \\
\left(\mathrm{g} \cdot \mathrm{m}^{-2} \cdot \mathrm{s}\right)\end{array}$ & Deviation \\
\hline \multirow{2}{*}{ Methanol } & 25 & 21 & 23 & $-9 \%$ \\
\cline { 2 - 5 } & 50 & 37 & 45 & $-18 \%$ \\
\hline \multirow{2}{*}{ n-Heptane } & 25 & 48 & 79 & $-39 \%$ \\
\cline { 2 - 6 } & 50 & 86 & 158 & $-46 \%$ \\
\hline
\end{tabular}

The latent heat of vaporization $\left(L_{v}\right.$, the denominator in Eq. (2)), is a well-known property of the liquid. Thus, the main source of uncertainty stems from the estimated average net heat flux over the liquid surface, $\dot{q}_{n e t}^{\prime}$. Given that $\dot{q}_{n e t}^{\prime \prime}=\dot{q}_{r a d}^{\prime \prime}$ where $\dot{q}_{r a d}^{\prime \prime}$ is the radiative heat flux exerted by the cone on the liquid surface, let us examine first the uncertainty in $\dot{q}_{\text {rad }}^{\prime \prime}$. 
In fact, $\dot{q}_{r a d}^{\prime}$ is calibrated experimentally by checking the radiative heat flux at the center of the cone and at a specific distance, $z$, from the edges. The general expression of $\dot{q}_{\text {rad }}^{\prime \prime}$ reads [20] (using the same nomenclature as in [20]):

$\dot{q}_{\text {rad }}^{\prime \prime}=F_{d 1-3} \varepsilon \sigma T^{4}$

where $d 1$ is the surface element (in the calibration process, it is located in the center), 3 is the internal surface of the radiating frustum (cone), $F_{d 1-3}$ is the view (configuration) factor from the former to the latter, $\varepsilon$ is the emissivity of the radiating cone elements, $\sigma$ is the Stefan-Boltzmann constant $\left(\sigma=5.67 \times 10^{-8} \mathrm{~W} / \mathrm{m}^{2} / \mathrm{K}^{4}\right)$ and $T$ is the temperature of the radiating elements. According to [20], the configuration factor is calculated as:

$$
F_{d 1-3}=\left\{\begin{array}{l}
\frac{r_{2}^{2}}{z^{2}+r_{2}^{2}}-\frac{r_{4}^{2}}{(z+h)^{2}+r_{4}^{2}} ; \text { if } a=0 \\
\frac{1}{2}\left[\left(1-\frac{1+H_{2}^{2}-R_{2}^{2}}{\sqrt{Z_{2}^{2}-4 R_{2}^{2}}}\right)-\left(1-\frac{1+H_{4}^{2}-R_{4}^{2}}{\sqrt{Z_{4}^{2}-4 R_{4}^{2}}}\right)\right] ; \text { if } a>0
\end{array}\right.
$$

where $a$ is the distance from the center and the remaining parameters are calculated as:

$H_{2}=\frac{z}{a} ; R_{2}=\frac{r_{2}}{a} ; Z_{2}=1+H_{2}^{2}+R_{2}^{2} ; H_{4}=\frac{h+z}{a} ; R_{4}=\frac{r_{4}}{a} ; Z_{4}=1+H_{4}^{2}+R_{4}^{2}$

The parameters $r_{2}, r_{4}$ and $h$ are respectively the outer radius, the inner radius and the height of the cone. The values for the cone used in this work are $r_{2}=80 \mathrm{~mm}, r_{4}=40 \mathrm{~mm}$ and $h=68 \mathrm{~mm}$ (see Fig. 1).

As shown in Fig. 1, the surface of the liquid is at a distance of $40 \mathrm{~mm}$ from the edge of the cone. Assuming that at the start of the test and in the center of the liquid surface (i.e., $z=40 \mathrm{~mm}$ and $a$ $=0 \mathrm{~mm}$ ) the view factor is taken as $F=1$, it is important to consider the initial horizontal variation of $F$. Based on Eqs. (5) and (6), the average view factor at the start of the simulation is estimated as $F=0.95$. At the end of the test (which corresponds to $z=65 \mathrm{~mm}$ ) the average view factor becomes about $F=0.70$, which considers the variation in the radiative heat flux in both the horizontal and the vertical direction. The subsequent 'actual' and average radiative heat flux 
exerted at the surface of the liquid is thus 5 to $30 \%$ lower than the nominal irradiation level. This does not explain though fully the deviations in Table 3, especially for n-heptane.

Other elements of uncertainty are to be considered in the estimation of the net radiative heat flux to the liquid surface, such as the surface reflectivity of the liquid, the re-radiation of the liquid surface, and the conductive heat loss to the walls of the steel pan [21]. Preliminary calculations have shown that the influence of these aspects is not substantial and does not explain the deviations displayed in Table 3. This will be discussed further in the numerical modelling section.

Finally, it is likely that the potential accumulation of vapor in the chamber limits the evaporation process, making evaporation essentially driven by concentration gradients and not the heat flux at the surface, as in Eq. (2). Vapor accumulation is due to the fact that both n-heptane and methanol are 'heavier' than the surrounding air, with molecular weights of respectively 100 and $32 \mathrm{~g} / \mathrm{mol}$ in comparison to the molecular weight of air, which is $29 \mathrm{~g} / \mathrm{mol}$. Bearing in mind this accumulation of vapor, it is particularly important here to recall here the importance of step 11 in the experimental protocol by putting back the supply of air. This will lower the flammability limit of the mixture air-vapor in the chamber and avoid 'backdraft' when opening the door at the end of the test. It is also interesting to note that the deviations in Table 3 are higher for $\mathrm{n}$-heptane than for methanol, most likely because of more vapor accumulation (n-heptane being heavier than methanol). More vapor accumulation can also explain the higher deviations at higher heat fluxes.

\subsubsection{Liquid temperatures}

Figures 6 and 7 show the transient profiles of the liquid temperature in the center at respectively 20 and $6 \mathrm{~mm}$ from the bottom of the pan. The results show an overall good repeatability of the measurements. In Figs. 6 and 7, the horizontal lines indicate the boiling point (around $64.8^{\circ} \mathrm{C}$ for methanol in and $98.5^{\circ} \mathrm{C}$ for n-heptane) whereas the vertical lines indicate an estimate of the time at which the liquid surface reached the position of the thermocouple. This estimate is deduced from the transient profiles of the liquid height which are calculated from the MLRPUA profiles. 
It appears from all the results displayed in Figs. 6 and 7 that, after an initial heat-up stage, a plateau is established when the liquid surface reaches the thermocouple.

As expected, the heat-up stage (before reaching the plateau) is approximately doubled when the nominal radiative heat flux is doubled, regardless of the thermocouple position. Obviously, the heat-up stage is longer when the thermocouple is positioned further from the liquid surface. Besides, it is interesting to note that the heat-up stage for methanol is twice as long as for n-heptane. This is less obvious to explain quantitatively. Following the work of Prétrel [22], the plateau is interpreted as an indication of the time period during which the thermocouple is immersed in the top isothermal vaporizing layer (as sketched in Fig. 5). More particularly, multiplying the timeaveraged liquid regression velocity by the duration of the plateau gives an estimate of the vaporizing layer thickness. The following estimates have been found: $4.3 \pm 1.4 \mathrm{~mm}$ for H25, 2.7 $\pm 1.4 \mathrm{~mm}$ for H50, $3.6 \pm 0.3 \mathrm{~mm}$ for M25 and $4.9 \pm 0.4 \mathrm{~mm}$ for M25. The deviations reported here are calculated based solely on the repeatability of the tests. Other uncertainties related for example to the thermocouple bead diameter (of $1.5 \mathrm{~mm}$ ) or to the calculated average regression velocity should be considered. Nevertheless, the order of magnitude of the obtained values is in good agreement with the values reported [22] where for several other fuels and for flaming conditions, the vaporizing layer thickness is about $4 \mathrm{~mm}$. The steep temperature rise after each plateau indicates that the thermocouple temperature is left exposed to the radiative heat flux from the cone. Finally, we observed that the liquid temperature measurements near the burner wall (not shown here) are quite similar to those measured in the center. 

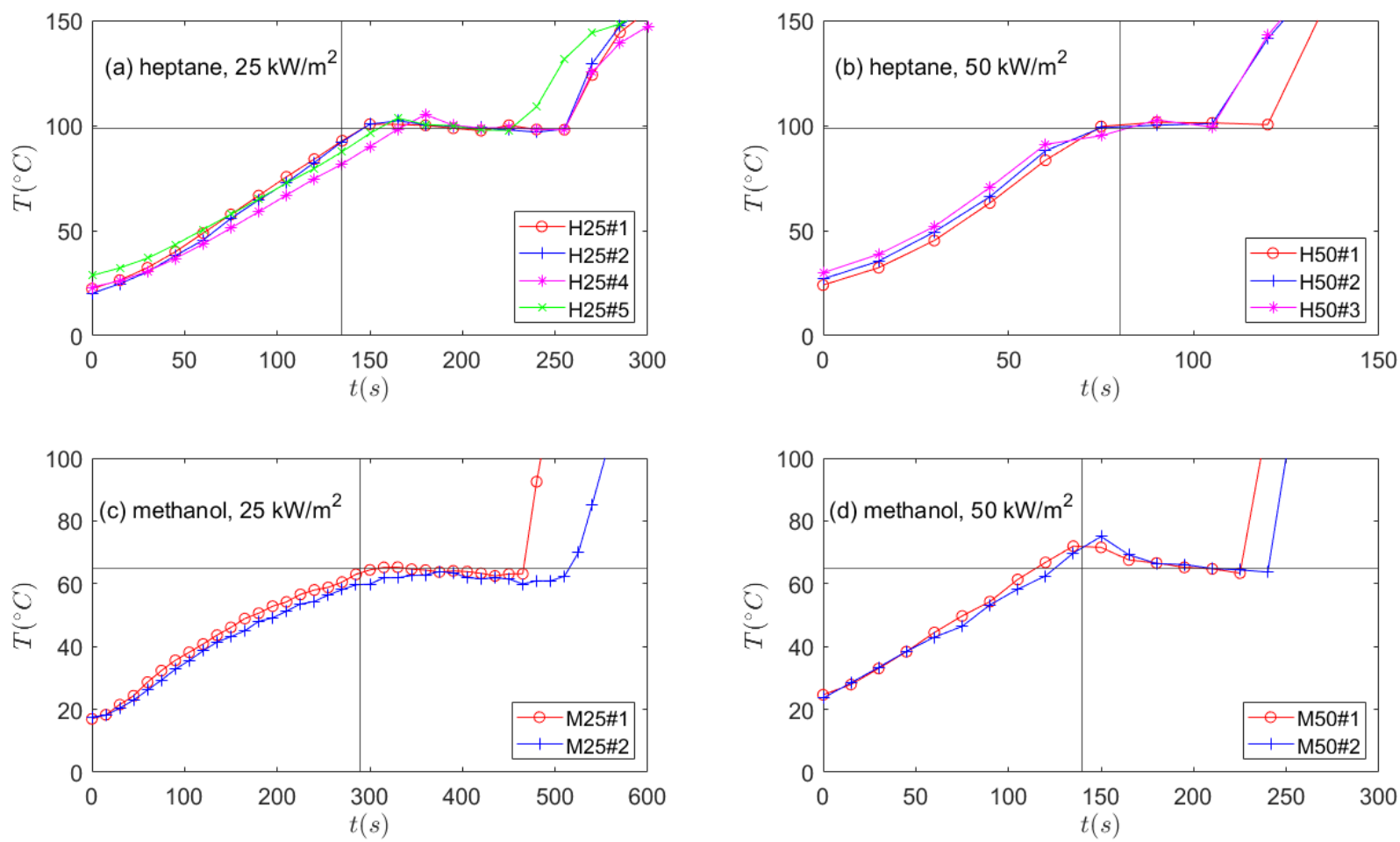

Figure 6-Transient profiles of liquid height and liquid temperature at $19 \mathrm{~mm}$ from the bottom of the pan. (a) H25. (b) H50. (c) M25. (d) M50.
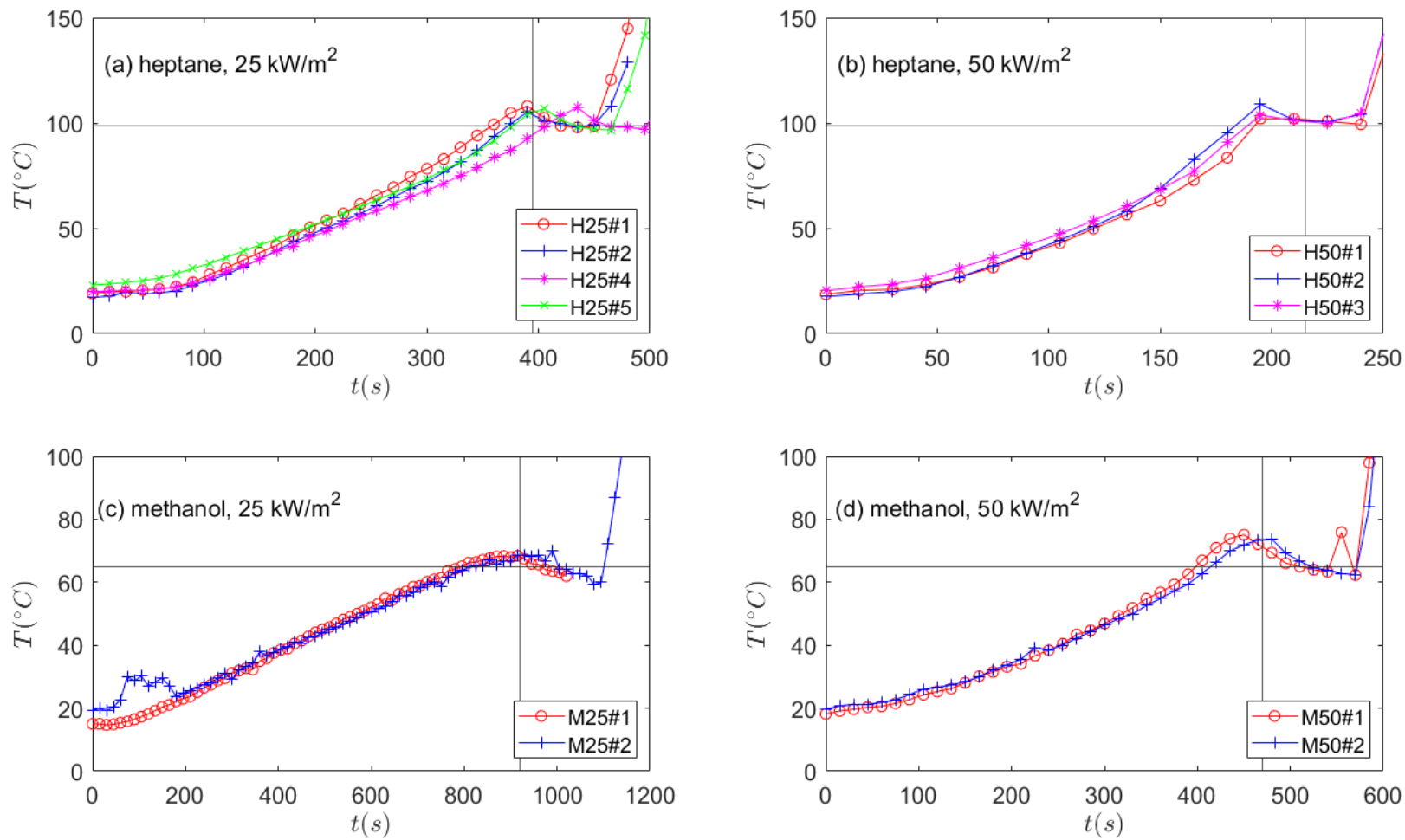

Figure 7 - Transient profiles of liquid height and liquid temperature at $6 \mathrm{~mm}$ from the bottom of the pan. (a) H25. (b) H50. (c) M25. (d) M5O. 


\section{Numerical modelling}

The main objective from the simulations carried out in this work is to focus on the heat-up and evaporation modelling of the liquid phase. A comprehensive sensitivity analysis is carried out in order to discuss the influence of several important physical parameters on the predicted thermal structure within the liquid and the subsequent evaporation rate.

Most of the simulations are performed using solely the 'solid phase' solver of the Fire Dynamics Simulator (FDS) (version 6.7.0) [11]. Although we are dealing in this work with liquids, not solids, the treatment of heat transfer in FDS is the same and is based on the solution of the 1-D Fourier's equation. More details are provided on the latter in the following section, along with details related to mass transfer (evaporation) modelling.

In addition to the condensed phase simulations, additional simulations have been carried out considering the liquid - gas coupling. Such simulations allow to quantify the effect of the vapor concentration gradient at the interface.

\subsection{Main equations}

\section{$\underline{3.1 .1 \text { Heat transfer }}$}

The 1-D Fourier's equation solved in FDS reads:

$\rho c \frac{\partial T(x, t)}{\partial t}=\frac{\partial}{\partial x}\left(k \frac{\partial T(x, t)}{\partial x}\right)+\dot{q}_{r}^{\prime \prime}$

where $\rho, k, c$ and $T$ are respectively the density, the thermal conductivity, the specific heat and the temperature of the liquid. The variables $t$ and $\dot{q}_{r}^{\prime \prime \prime}$ denote the time and the volumetric radiative heat source term within the liquid, respectively. The thermal boundary condition on the top surface of the liquid reads:

$-k \frac{\partial T}{\partial x}(0, t)=\dot{q}_{c, s}^{\prime \prime}+\dot{q}_{r, s}^{\prime \prime}-L_{v} \dot{m}^{\prime \prime}$

where $\dot{q}_{c, s}^{\prime \prime}$ and $\dot{q}_{r, s}^{\prime \prime}$ are respectively the convective and radiative heat fluxes at the surface, $L_{v}$ is the latent heat of vaporization and $\dot{m}^{\prime \prime}$ is the evaporation rate. In case of internal radiation, the net radiative heat flux at the surface should be set to zero. 
Note that, in order to eliminate the uncertainties related to convection, the latter is not considered here by setting the convective heat transfer coefficient to zero. This is deemed to be a reasonable assumption given that the cases at hand are cases of non-reacting (non-flaming) evaporating liquids with relatively low temperature differences between the liquid surfaces and the surrounding environment.

The radiative heat flux at the surface is taken as zero when considering a source term for in-depth radiation, see Eq. (1). The latter is calculated by distributing the heat flux at the surface over a predefined depth (length scale for in-depth radiation). The transport of heat radiation inside the liquid layer is solved using a 'two-flux' model based on the Schuster-Schwarzschild approximation $[6,11]$. A key quantity in this calculation is the absorption coefficient of the liquid, $\kappa$.

Equation (7) is solved using a finite differences scheme using a uniform meshing. The cell size is calculated as:

$\Delta x=\Phi \sqrt{\frac{\tau k}{\rho c}}$

where $\Phi$ is a 'cell size factor' and $\tau$ is a time constant, taken as $\tau=1 \mathrm{~s}$. In the simulations carried out in this paper the cell size for the liquid phase is taken as $\Delta x=0.5 \mathrm{~mm}$. A preliminary cell sensitivity analysis (not shown here) has shown that this is a suitable value for the present calculations. Similarly, a time step of $\Delta t=0.1 \mathrm{~s}$ is selected based on a sensitivity analysis.

A $2 \mathrm{~mm}$-depth steel layer followed by a $58 \mathrm{~mm}$-depth calcium silicate layer are positioned beneath the $25 \mathrm{~mm}$-depth layer of n-heptane. The bottom surface of the calcium silicate layer is left 'exposed' (default bottom boundary condition in FDS) and is thus subjected to convective cooling. The thermal properties used for steel and calcium silicate are provided in Table 4.

Table 4 - Thermal properties of steel and calcium silicate used in the simulations.

\begin{tabular}{|l|l|l|l|}
\hline & $\rho\left(\mathrm{kg} / \mathrm{m}^{3}\right)$ & $k(\mathrm{~W} / \mathrm{m} . \mathrm{K})$ & $c_{p}(\mathrm{~kJ} / \mathrm{kg} . \mathrm{K})$ \\
\hline Steel & 8000 & 40 & 0.4 \\
\hline Calcium silicate & 200 & 0.1 & 1.0 \\
\hline
\end{tabular}




\subsubsection{Mass transfer}

The evaporation rate is calculated as [6]:

$\dot{m}=\left(\frac{\operatorname{Sh} \times D_{v}}{L}\right)\left(\frac{p \times M W_{F}}{R T_{g}}\right) \ln \left(\frac{X_{g}-1}{X_{l}-1}\right)$

where Sh is the Sherwood number, $D_{v}$ is the diffusion coefficient of liquid vapor in the surrounding environment, $L$ is a length scale for convective heat and mass transfer (taken by default as $L=1$ m) and $X_{g}$ and $X_{l}$ are the molar concentrations of vapor in respectively the surrounding gas and at the liquid surface.

The Sherwood number is calculated as [6]:

$\mathrm{Sh}=0.037 \mathrm{Sc}^{1 / 3} \mathrm{Re}^{4 / 5}$

where $\mathrm{Sc}$ is the Schmidt number taken as $\mathrm{Sc}=0.6$ and $\mathrm{Re}$ is the Reynolds number. The latter is calculated as [6]:

$\operatorname{Re}=\max \left(5 \times 10^{5}, \frac{\rho\|u\| L}{\mu}\right)$

where $\rho,\|u\|$ and $\mu$ are the density, the velocity and the dynamic viscosity of the surrounding gas.

\subsection{List of test cases}

In the simulations carried out in this work, we examined the effect of the following parameters: (1) the thermal conductivity of the liquid, (2) its absorption coefficient, and (3) the value of the heat flux at the surface.

The thermal conductivity prescribed in the simulations is called hereafter an 'effective thermal conductivity' and is calculated as:

$k_{e f f}=\mathrm{Nu}_{i} \times k$

where $k$ is the actual conductivity of the liquid and $\mathrm{Nu}_{i}$ is the internal Nusselt number, which represents the enhancement in heat transfer within the liquid due to convective motion (partly induced by in-depth radiation). The main idea behind this approach is to 'by-pass' the complexity induced by explicitly modelling convective motion in the liquid by solving the Navier-Stokes equations therein. Two approaches have been developed in [6] and [9] in order to calculate $\mathrm{Nu}_{i}$. 
This is not discussed in this paper. Instead, only the order of magnitude of $\mathrm{Nu}_{i}$ is discussed by examining four values, i.e., $\mathrm{Nu}_{i}=1,10,20$ and 100 .

The absorption coefficient, $\kappa$, of the liquid is another important unknown of the problem. Two methods have been developed in [6] to estimate $\kappa$ for several liquids. In this paper, only the order of magnitude of $\kappa$ is investigated by considering three values, i.e., $\kappa=100,1000$ and 10000 .

Regarding the value of the heat flux at the surface, we examined (i) the effect of the reduction in view factor as the fuel surface regresses with time, (ii) the effect of a reduction in the nominal heat flux (that will be discussed later on in the analysis of the results) and (iii) the effect of the length scale $L$.

The comprehensive sensitivity analysis on the parameters discussed above has been focused on the case of n-heptane with a heat flux of $50 \mathrm{~kW} / \mathrm{m}^{2}$ (see in Table 5 the list of corresponding numerical simulations).

Table 5 - List of numerical simulations for the case of n-heptane with a heat flux of $50 \mathrm{~kW} / \mathrm{m}^{2}$.

The line highlighted in grey represents the base case for the sensitivity analysis.

\begin{tabular}{|l|l|l|l|l|l|l|l|}
\hline Test ID & $\mathrm{Nu}_{i}$ & $\kappa\left(\mathrm{m}^{-1}\right)$ & $\begin{array}{l}\text { Reduction in } \\
\text { view factor }\end{array}$ & $\begin{array}{l}\text { Nominal heat } \\
\text { flux }\left(\mathrm{kW} \cdot \mathrm{m}^{-}\right. \\
2\end{array}$ & $L(\mathrm{~m})$ & $\Phi(-)$ & $\begin{array}{l}\text { Liquid - } \\
\text { gas } \\
\text { coupling }\end{array}$ \\
\hline H50_1 & 1 & $10^{3}$ & Yes & 50 & 1 & 1.64 & No \\
\hline H50_2 & 10 & $10^{3}$ & Yes & 50 & 1 & 0.52 & No \\
\hline H50_3 & 20 & $10^{3}$ & Yes & 50 & 1 & 0.37 & No \\
\hline H50_4 & 100 & $10^{3}$ & Yes & 50 & 1 & 0.16 & No \\
\hline H50_5 & 20 & $10^{2}$ & Yes & 50 & 1 & 0.37 & No \\
\hline H50_6 & 20 & $10^{4}$ & Yes & 50 & 1 & 0.37 & No \\
\hline H50_7 & 20 & $10^{3}$ & No & 50 & 1 & 0.37 & No \\
\hline H50_8 & 20 & $10^{3}$ & Yes & 40 & 1 & 0.37 & No \\
\hline H50_9 & 20 & $10^{3}$ & Yes & 40 & 1 & 0.37 & Yes \\
\hline H50_10 & 20 & $10^{3}$ & Yes & 40 & 0.1 & 0.37 & Yes \\
\hline
\end{tabular}


Besides the detailed sensitivity analysis carried out for H50, numerical simulations for H25, M25 and M50 will be presented and discussed at the end of this section.

\subsection{Results}

\subsubsection{Effect of the prescribed $\mathrm{Nu}_{i}$}

Figure 8 displays the influence of the prescribed Nusselt number on the simulation results.
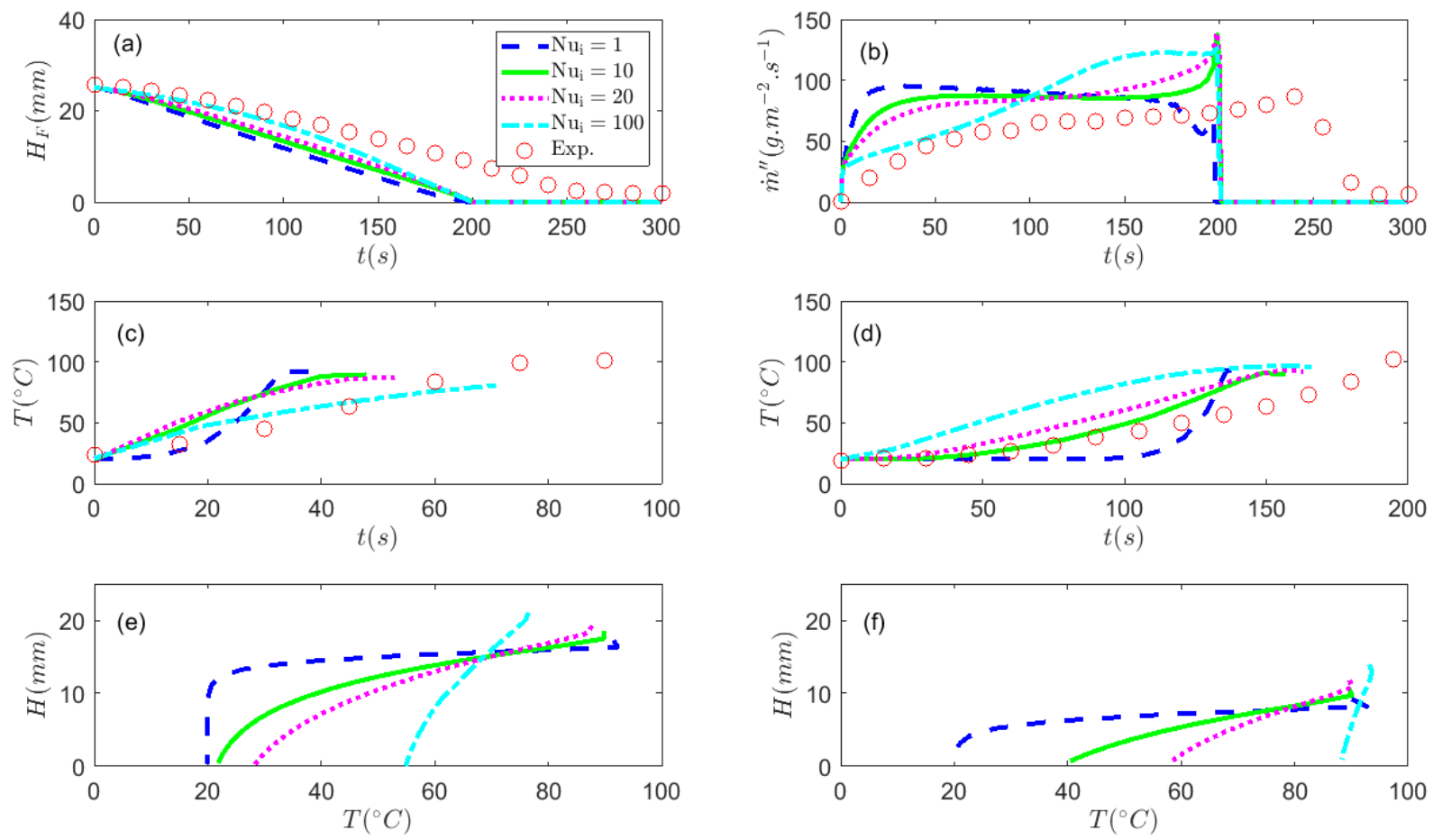

Figure 8 - Experimental and numerical results (with several values of $\mathrm{Nu}_{i}$ ) for the heptane liquid pool at $50 \mathrm{~kW} / \mathrm{m}^{2}$. (a) Transient profiles of liquid height. (b) Transient profiles of the MLRPUA. (c) Transient profiles of the liquid temperature at $19 \mathrm{~mm}$ from the pool bottom. (d) Transient profiles of the liquid temperature at $6 \mathrm{~mm}$ from the pool bottom. (e) Thermal structure of the liquid at $60 \mathrm{~s} .(f)$ Thermal structure of the liquid at $120 \mathrm{~s}$.

Figure 8a shows that the increase in the thermal conductivity of the liquid has no effect on the predicted evaporation time of the liquid (i.e., full consumption of the liquid), which is around 210 s, about 1 minute sooner that the measured evaporation time. However, the simulated temporal profiles of the liquid height are different. For example, with $\mathrm{Nu}_{i}=1$, the profile is nearly constant 
during the evaporation time, whereas for $\mathrm{Nu}_{i}=100$, the simulated regression rate of the fuel appears to be as slow as the measured regression rate in the early stages of the evaporation, up to around 75 s. However, a 'sudden' acceleration occurs from that time onwards, yielding the same evaporation time as the other simulations with $\mathrm{Nu}_{i}=1,20$, and 100.

The change in regression rate as a function of time is best visualized in Fig. 8b where the results are displayed in terms of evaporation rate (or MLRPUA), which is directly proportional to the derivative of the fuel height with time. The profile with $\mathrm{Nu}_{i}=1$ shows a quasi-steady stage starting from around $20 \mathrm{~s}$. During this quasi-steady stage, the evaporation rate is actually slightly decreasing. A slight increase occurs shortly before the time to complete evaporation of the liquid. At the other end of the range, the profile with $\mathrm{Nu}_{i}=100$ shows an increase in the evaporation rate up to $130 \mathrm{~s}$ and then a quasi-steady state before complete evaporation at around $210 \mathrm{~s}$, without the occurrence of a peak. The profiles with $\mathrm{Nu}_{i}=10$ and $\mathrm{Nu}_{i}=20$ appear to be, qualitatively, speaking, the closest to the experimental profile: the evaporation rate reaches a quasi-steady state within the first 20 to $50 \mathrm{~s}$ and exhibits an increase shortly before the time to complete evaporation of the liquid. The occurrence of such a peak before complete evaporation is linked to the level of preheating of the liquid. With $\mathrm{Nu}_{i}=20$, the heat-up is more 'gradual' than with $\mathrm{Nu}_{i}=10$ and thus, the increase in the evaporation rate (after the steady-state stage) occurs sooner, which appears to be in a 'better' qualitative agreement with the experimental data. Except for the $\mathrm{Nu}_{i}=1$, the peak evaporation rate prior to complete evaporation is overestimated by about $100 \%$ and maximum temperatures are underestimated by about $10^{\circ} \mathrm{C}$.

The heat-up is further analyzed by examining the temperature profiles in Figs. 8c to 8f. Figure 8d shows the temporal profile of the liquid temperature at (only) $6 \mathrm{~mm}$ from the bottom of the pan, which is indicative of the level of preheating before complete evaporation. The results show that, for $\mathrm{Nu}_{i}=1$, the preheating starts only at around $120 \mathrm{~s}$ because of the relatively low thermal conductivity (in comparison with the other cases). Then, within a relatively short period (in comparison with the other cases) the liquid reaches the boiling point. For higher values of $\mathrm{Nu}_{i}$, the preheating occurs sooner (because of the higher thermal conductivity) and is more gradual. A value of $\mathrm{Nu}_{i}=10$ appears to give the best agreement with the experimental data in Fig. 8d. At $19 \mathrm{~mm}$ from the bottom of the pan (corresponding to initially $5 \mathrm{~mm}$ below the liquid surface), a value of $\mathrm{Nu}_{i}=100$ (and not $\mathrm{Nu}_{i}=10$ ) appears to give the best agreement with the experimental data, see 
Fig. 8c. This is likely indicative of a more pronounced heat-up near the surface due to, for instance, convective motion induced by in-depth radiation, as discussed in [6] and [9, 10]. It is also indicative of the limitation of the approach described in Eq. (13). A dynamic procedure to calculate $\mathrm{Nu}_{i}$ as a function of space and time could be an interesting solution to develop in the future, but this is out of the scope of the current paper.

A more general overview of the liquid thermal structure at $t=60 \mathrm{~s}$ and $t=120 \mathrm{~s}$ is provided in respectively Figs. 8e and 8f. The highest prescribed thermal conductivity, which corresponds to $\mathrm{Nu}_{i}=100$, resulted in a thermally thin behavior of the liquid from around $120 \mathrm{~s}$ onwards. Figure $8 \mathrm{f}$ shows indeed a 'nearly' uniform temperature profile across the liquid depth at $120 \mathrm{~s}$ for $\mathrm{Nu}_{i}=$ 100. This thermally thin behavior explains the absence of a peak in the evaporation rate profile before complete evaporation as opposed to the profiles with lower values of $\mathrm{Nu}_{i}$. With $\mathrm{Nu}_{i}=1$, a sharp temperature gradient exists between an upper 'hot' layer and a lower 'cold' layer.

Regarding the comparison of the simulation results with the experimental data, one can conclude at this level that the value of $\mathrm{Nu}_{i}=20$ provides the best overall agreement with the experimental data for the evaporation rate and the liquid temperature. This should not be seen as a mere 'tuning exercise', but rather a clear indication (an evidence) of the importance to consider the enhanced heat transfer within the liquid, most likely due to fluid motion. The value of $\mathrm{Nu}_{i}=20$ is only an order of magnitude; it appears to be suitable for the case at hand. It may be also of interest to hint already at a more sophisticated approach where $\mathrm{Nu}_{i}$ would vary with time, but this is out of scope for the current paper.

\subsubsection{Effect of the prescribed $\kappa$}

Figure 9 shows the effect of the absorption coefficient on the evaporation rate and the thermal structure of the liquid. The temporal profiles of the flame height and the evaporation rates displayed in Figs. 9a and 9b are very similar when prescribing $\kappa=1000$ or $10000 \mathrm{~m}^{-1}$. Reducing

the absorption coefficient further to $\kappa=100 \mathrm{~m}^{-1}$ resulted in a slower regression rate in the early stage of the evaporation, which is in a better agreement with the experimental data. However, the MLRPUA peak reached before complete evaporation is more than $50 \%$ higher than the other simulation results and about $100 \%$ higher than the peak experimental value. Similarly to the 
sensitivity analysis on $\mathrm{Nu}_{i}$, this result potentially hints at the need to account for a time-dependent absorption coefficient, $\kappa$. Except for the $\kappa=100 \mathrm{~m}^{-1}$, the peak evaporation rate prior to complete evaporation is overestimated by about $100 \%$ and maximum temperatures are underestimated by about $10^{\circ} \mathrm{C}$.

Figure $9 \mathrm{c}$ shows that the near surface temperature in the early stages does not appear to be sensitive to the value of the absorption coefficient. The influence of $\kappa$ is more visible when considering the liquid temperature evolution at $6 \mathrm{~mm}$ from the bottom of the pan, see Fig. 9d. More particularly, when $\kappa=100 \mathrm{~m}^{-1}$, the heat up is faster because the in-depth radiation source term is distributed over a deeper portion of the liquid ( $\kappa$ is inversely proportional to the in-depth radiation 'length scale'). It is important though to mention that the obtained temperature profile becomes 'unphysical' after about $120 \mathrm{~s}$ because the liquid temperature exceeds the boiling point.
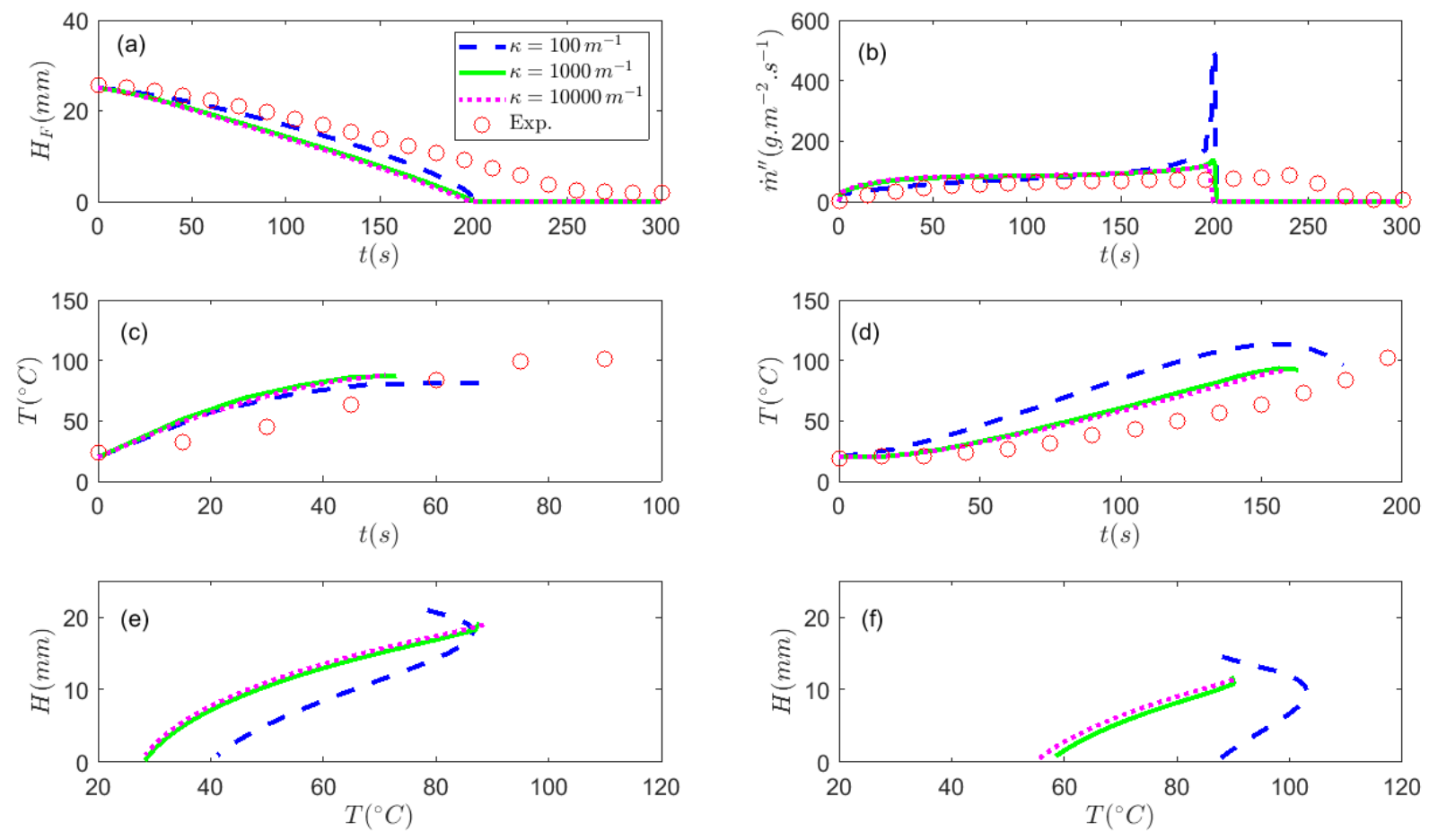

Figure 9 - Experimental and numerical results (with several values of $\kappa$ ) for the heptane liquid pool at $50 \mathrm{~kW} / \mathrm{m}^{2}$. (a) Transient profiles of liquid height. (b) Transient profiles of the MLRPUA. (c) Transient profiles of the liquid temperature at $19 \mathrm{~mm}$ from the pool bottom. (d) Transient profiles of the liquid temperature at $6 \mathrm{~mm}$ from the pool bottom. (e) Thermal structure of the liquid at $60 \mathrm{~s}$. (f) Thermal structure of the liquid at $120 \mathrm{~s}$. 
The liquid thermal structure displayed in Figs. 9e and 9f shows 'inverse temperature' profiles for $\kappa=100 \mathrm{~m}^{-1}$ at $60 \mathrm{~s}$ and $120 \mathrm{~s}$. Furthermore, at $120 \mathrm{~s}$, a significant volume of the liquid is at a temperature that is above the boiling point of $98.5^{\circ} \mathrm{C}$. These results confirm that a value of $\kappa=100$ $\mathrm{m}^{-1}$ is not appropriate for the case at hand. The profiles with $\kappa=1000$ and $10000 \mathrm{~m}^{-1}$, which are quite similar, are more plausible. We note however that for $\kappa=1000$ there is a $1 \mathrm{~mm}$-deep (nearly) uniform top layer, which is not the case for $\kappa=10000$.

\subsubsection{Effect of the prescribed heat flux}

Figure 10 shows that, contrarily to the previous simulations, changing the heat flux value at the surface does have, as expected, an effect on the time to complete evaporation. Theoretically speaking, this time can be estimated as:

$t_{\text {evap }}=\frac{\left[L_{v}+c_{p}\left(T_{b}-T_{l}\right)\right] \times V \times \rho}{\dot{q}^{\prime \prime}{ }_{\text {rad }} \times A}$

where $V$ and $A$ denote the volume and the top surface area of the liquid.
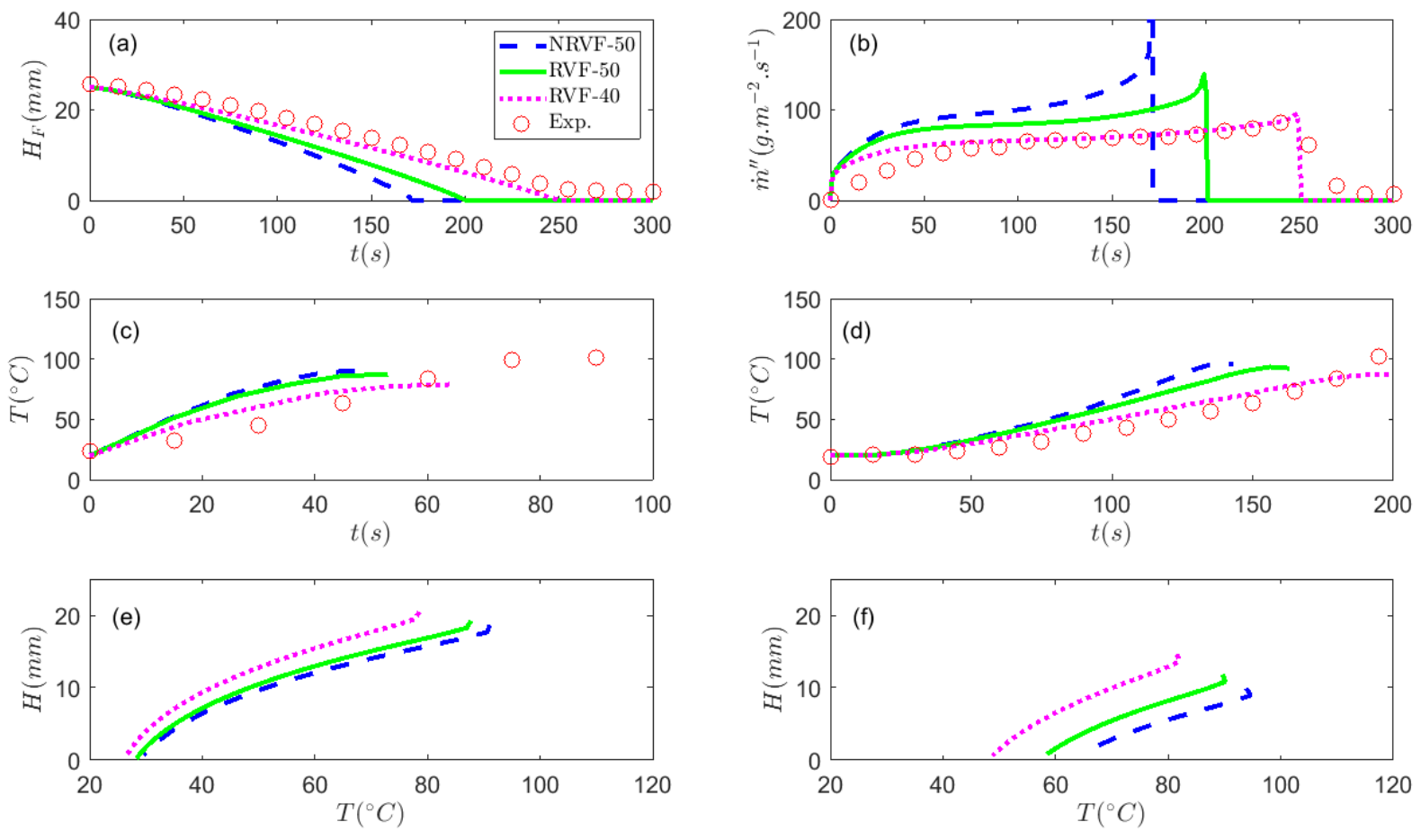

Figure 10-Experimental and numerical results (with several values of the radiative heat flux) for the heptane liquid pool at $50 \mathrm{~kW} / \mathrm{m}^{2}$. (a) Transient profiles of liquid height. (b) Transient profiles of the MLRPUA. (c) Transient profiles of the liquid temperature at $19 \mathrm{~mm}$ from the pool bottom. 
(d) Transient profiles of the liquid temperature at $6 \mathrm{~mm}$ from the pool bottom. (e) Thermal structure of the liquid at $60 \mathrm{~s}$. (f) Thermal structure of the liquid at $120 \mathrm{~s}$.

A nominal heat flux of $50 \mathrm{~kW} / \mathrm{m}^{2}$ with no reduction in the view factor (NRVF) yielded, in accordance with Eq. (14), an evaporation time of $168 \mathrm{~s}$, whereas the reduction in view factor (RVF) yielded an evaporation time of $210 \mathrm{~s}$. Finally, reducing the prescribed nominal heat flux to 40 $\mathrm{kW} / \mathrm{m}^{2}$ (along with the reduction in the view factor) resulted in a better agreement with the experimental profile (the predicted evaporation time is $250 \mathrm{~s}$ ). Figure $10 \mathrm{~b}$ shows clearly that the latter combination provides a very good agreement in terms of evaporation rate, especially from $100 \mathrm{~s}$ onwards. Furthermore, when the nominal heat flux is set to $50 \mathrm{~kW} / \mathrm{m}^{2}$, the comparison of the results with or without the reduction in the view factor clearly shows the importance of the latter. For example, the peak value for the evaporation rate is reduced by about $45 \%$.

Figures 10c and 10d show, as expected, that the lower the heat flux at the surface the slower the liquid heat-up. More particularly, similarly to the evaporation rate, a nominal heat flux of 40 $\mathrm{kW} / \mathrm{m}^{2}$ along with a reduction in the view factor yields a very good agreement for the liquid temperature evolution, especially at $6 \mathrm{~mm}$ from the bottom of the pan, see Fig. 10d.

Figures $10 \mathrm{e}$ and $10 \mathrm{f}$ show that the change in the heat flux at the liquid surface does not yield a qualitative change in the thermal structure of the liquid. However, it is clear, as expected, that the higher the heat flux the higher the liquid temperature.

The need to reduce the nominal heat flux from $50 \mathrm{~kW} / \mathrm{m}^{2}$ to $40 \mathrm{~kW} / \mathrm{m}^{2}$ can be explained by several factors. One of these factors is the reflectivity of the liquid which is taken for example in [16] to be 0.08 for a wide range of liquids, this would bring the actual nominal heat flux to be $46 \mathrm{~kW} / \mathrm{m} 2$. Another factor could be related to the fact that the rim surrounding the liquid surface may cause a further reduction in the view factor, which is not considered here. Finally, the accumulation of nheptane vapor which is heavier than the surrounding air could have yielded an attenuation of radiation from the cone. A more detailed analysis of these aspects will be carried out in the future.

\subsubsection{Effect of the liquid - gas coupling}

Figure 11 shows that when the liquid - gas phase coupling is considered in the simulations, the evaporation rate is, to some extent, reduced significantly in the first 25 seconds. However, from $25 \mathrm{~s}$ onwards, the deviations did not exceed $10 \%$. The reduction in evaporation rate is explained 
by the fuel vapor accumulation near the surface (i.e., increased value of $X_{g}$ ) which reduces the logarithmic term in Eq. (10). The time for complete evaporation is increased by about $14 \mathrm{~s}$ which is not negligible, but the effect of the prescribed heat flux, as discussed in section 3.3.3, has clearly a more dominant effect (on the time for complete evaporation).
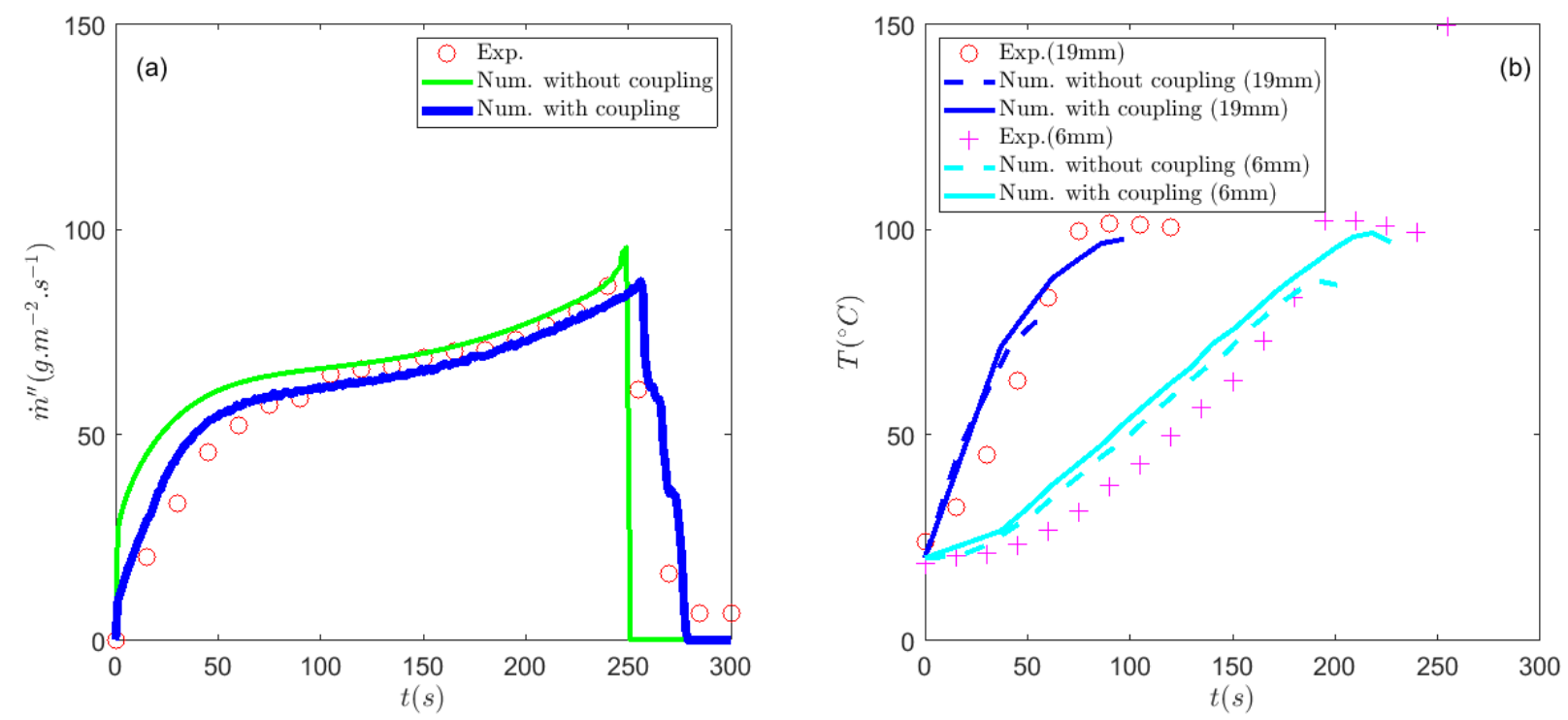

Figure 11 -Influence of the liquid-gas coupling on the simulated evaporation rate for the heptane liquid pool at $50 \mathrm{~kW} / \mathrm{m}^{2}$.

\subsubsection{Effect of the length scale for convective mass transfer}

All the numerical profiles for the evaporation rate displayed in Figs. 8b, 9b, 10b and 11a show a common feature that has not been discussed yet, which consists in the fact that the evaporation rate after the first time step is a constant, which varies depending whether liquid - gas coupling is considered or not, but is independent of all the other settings discussed so far. This can be explained by the minimum constant value of the Reynolds number in Eq. (12), which corresponds to a minimum flow rate of liquid vapor at the start of the simulation. If the Reynolds number is not a function of the length scale $L$, the evaporation rate (in the early stages) becomes inversely proportional to $L$. Figure 12a shows indeed that, by increasing the length scale from $L=1 \mathrm{~m}$ (default value in FDS) to $L=0.1 \mathrm{~m}$ (the side length of the pan), the evaporation rate is significantly increased from the first time step and remains higher than the experimental measurements and the results with $L=1 \mathrm{~m}$. The effect on the temperature profiles, as shown in Fig. 12b, is moderate. It 
is noted that the effect of the length-scale $L$ is much more pronounced when liquid - gas coupling is not taken into account (not shown here).
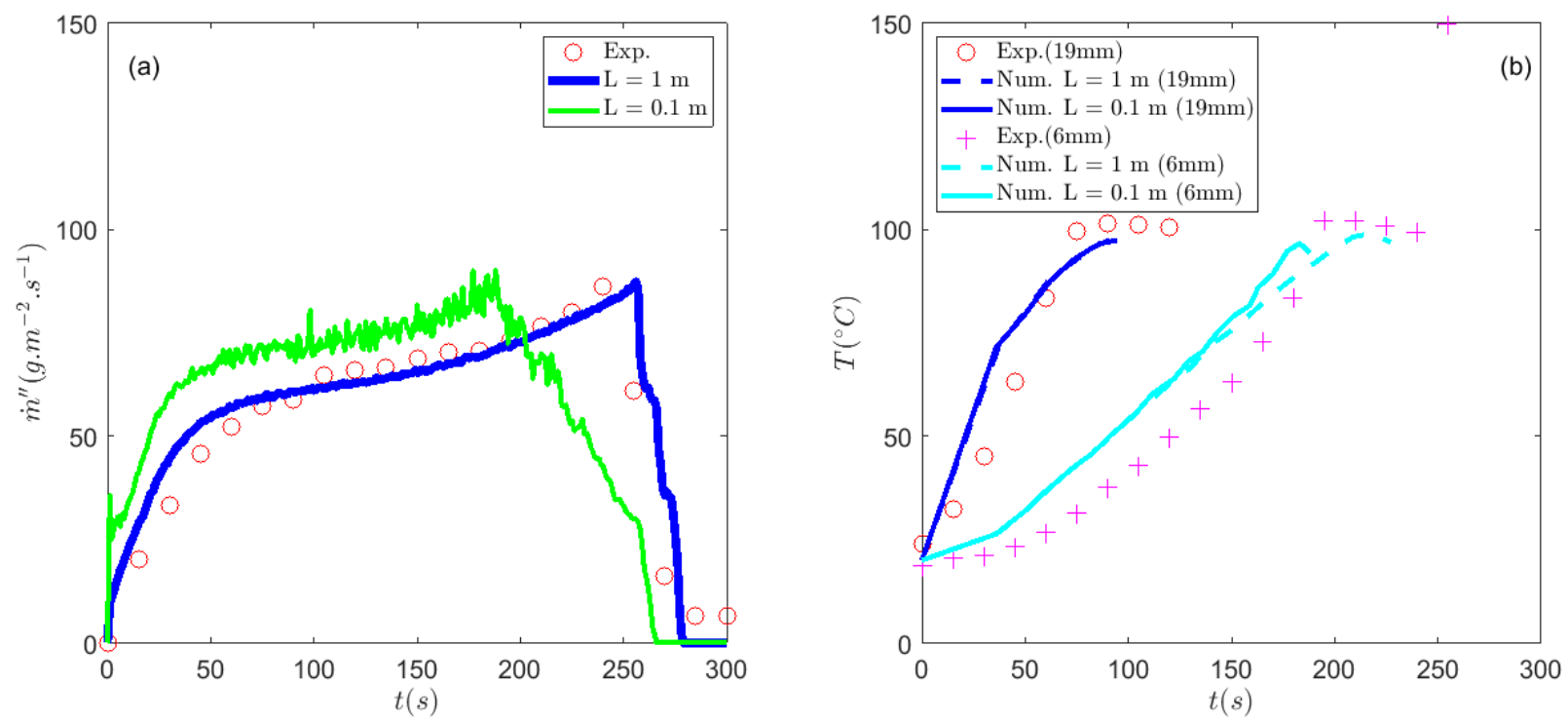

Figure 12 - Influence of the length scale L on the simulation results for the heptane liquid pool at $50 \mathrm{~kW} / \mathrm{m}^{2}$. (a) Evaporation rate. (b) Surface temperature.

It is quite surprising that a more 'appropriate' length scale for heat and mass transfer, i.e., the side length of the pan, $L=0.1 \mathrm{~m}$, provides 'worse' results in comparison with the default setting of $L$ $=1 \mathrm{~m}$. In fact, we believe that the expression for the Sherwood number based on a correlation for a turbulent forced convection flow regime may not be appropriate for liquid evaporation in the configuration of interest, as explained and discussed in [5]. The alternative option would be to rely on a correlation for a laminar natural convection flow regime (as discussed in [5]). This will be explored in the future for the cases examined in this work.

\subsubsection{Results for $\mathrm{n}$-heptane at $25 \mathrm{~kW} / \mathrm{m}^{2}$ and methanol at 25 and $50 \mathrm{~kW} / \mathrm{m}^{2}$}

After the sensitivity analysis carried out for the case of n-heptane at $50 \mathrm{~kW} / \mathrm{m}^{2}$, some parameters have been kept the same for the simulation of the remainder of the test cases. These parameters are: $\mathrm{Nu}_{i}=20, \kappa=1000 \mathrm{~m}^{-1}$ and $L=1 \mathrm{~m}$ (the default value in FDS). Liquid - gas coupling has also been considered in the remainder of the simulations. The cell size in the three simulations has also 
been kept at $\Delta x=0.5 \mathrm{~mm}$. Due to the different thermal properties, the cell size reduction factor for methanol is $\Phi=0.35$, instead of $\Phi=0.37$ for $n$-heptane. Furthermore, the reduction in view factor has been considered in the simulations. Similarly to the previous simulations discussed above, the view factor at the start of the simulations has been set to 0.95 (see Table 6) to account for the radiative heat flux reduction in the radial direction. During the course of the simulations, the view factor reduces gradually as the fuel surface regresses to reach a value of 0.70 (see Table 6) at the end of the simulation (after complete consumption of the fuel). Ideally, the view factor should be dynamically adjusted during the simulation as a function of the fuel height, which requires modifications in the source code. Instead, for the sake of simplicity, a linear decrease (with time) has been prescribed, which can be a 'fair' approximation of the decrease in fuel height with time. This requires an a priori knowledge of the time to complete evaporation of the liquid. Finally, in the a posteriori simulations performed in this section, the nominal heat flux (see Table 6) has been selected so that a good agreement is obtained for the MLRPUA, as displayed in Figs. 13a, 14a and $15 \mathrm{a}$.

Table 6 - View factor(s) and nominal heat fluxes used for the simulations of the cases of nheptane at $25 \mathrm{~kW} / \mathrm{m}^{2}$ and methanol at 25 and $50 \mathrm{~kW} / \mathrm{m}^{2}$.

\begin{tabular}{|l|l|l|l|l|}
\hline Test ID & \multicolumn{3}{|c|}{ View factor } & Nominal heat flux $\left(\mathrm{kW} \cdot \mathrm{m}^{-2}\right)$ \\
\cline { 4 - 5 } & \multicolumn{2}{|c|}{} & Value & Deviation \\
\hline $\mathrm{H} 25$ & $@ \mathrm{t}=0 \mathrm{~s}, \mathrm{VF}=0.95$ & $@ \mathrm{t}=480 \mathrm{~s}, \mathrm{VF}=0.70$ & 20 & $-20 \%$ \\
\hline $\mathrm{M} 25$ & $@ \mathrm{t}=0 \mathrm{~s}, \mathrm{VF}=0.95$ & $@ \mathrm{t}=1160 \mathrm{~s}, \mathrm{VF}=0.70$ & 25 & $0 \%$ \\
\hline $\mathrm{M} 50$ & $@ \mathrm{t}=0 \mathrm{~s}, \mathrm{VF}=0.95$ & $@ \mathrm{t}=580 \mathrm{~s}, \mathrm{VF}=0.70$ & 45 & $-10 \%$ \\
\hline
\end{tabular}

Figure 13a shows that, similarly to $\mathrm{H} 50$ and in addition to the reduction in view factor, a reduction in the nominal radiative heat flux by $20 \%$ has been 'necessary' to obtain a good agreement in MLRPUA for H25. Similar discrepancies remain though such as the overestimation of the MLRPUA at the initial stages. The results for the liquid temperature, displayed in Fig 13b, show that the agreement is rather good for the top thermocouple (at $19 \mathrm{~mm}$ from the bottom of the pan), whereas the liquid heat-up is faster that recorded at $6 \mathrm{~mm}$ from the bottom of the pan. 

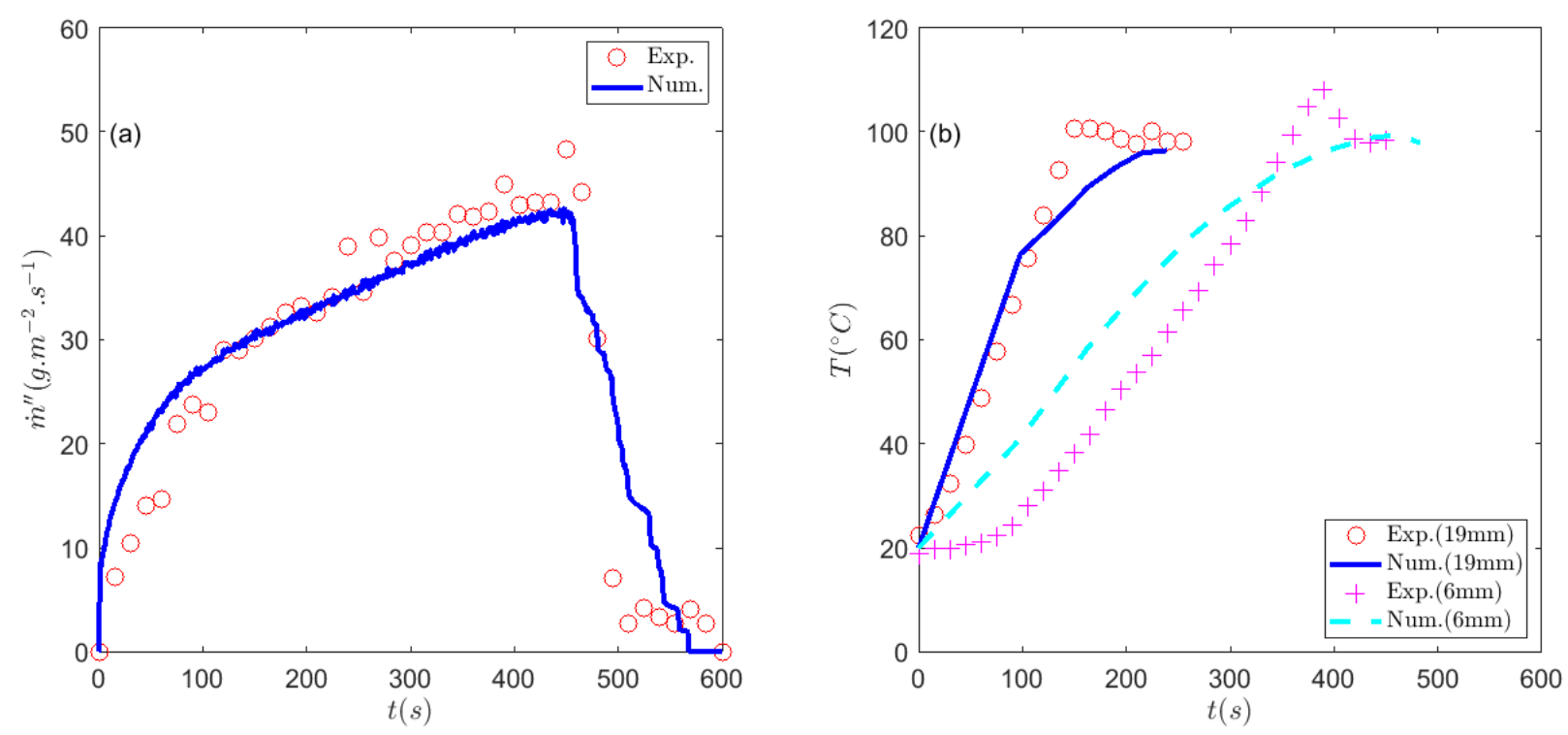

Figure 13 - Experimental and numerical results for the heptane liquid pool at $25 \mathrm{~kW} / \mathrm{m}^{2}$. (a) Transient profiles of MLRPUA. (b) Transient profiles of the liquid temperature at 19 and $6 \mathrm{~mm}$ from the pool bottom.

As opposed to $n$-heptane, Figs. $14 \mathrm{a}$ and $14 \mathrm{~b}$ for methanol show a good agreement in the MLRPUA without having to reduce the nominal heat flux for M25 and reducing it by 'only' 10\% for M50, which is in line with the differences between the two fuels discussed above (e.g., more vapor accumulation for n-heptane). However, the liquid temperature profiles are not well predicted. The simulations show a steeper increase at the initial stage. Nevertheless, the 'saturation' temperature around a value below the boiling point at a more developed stage is well predicted. The discrepancies in the transient stage can be explained by the fact $\mathrm{Nu}_{i}=20$ and $\kappa=1000 \mathrm{~m}^{-1}$ are not necessarily suitable values, especially that $\kappa$ is clearly a fuel-dependent property and thus, a value initially 'calibrated' for n-heptane may not be suitable for methanol. More generally, one should bear in mind that the values of $\mathrm{Nu}_{i}$ and $\kappa$ depend on the model and its weaknesses and should not be regarded as 'true' physical characteristics. 

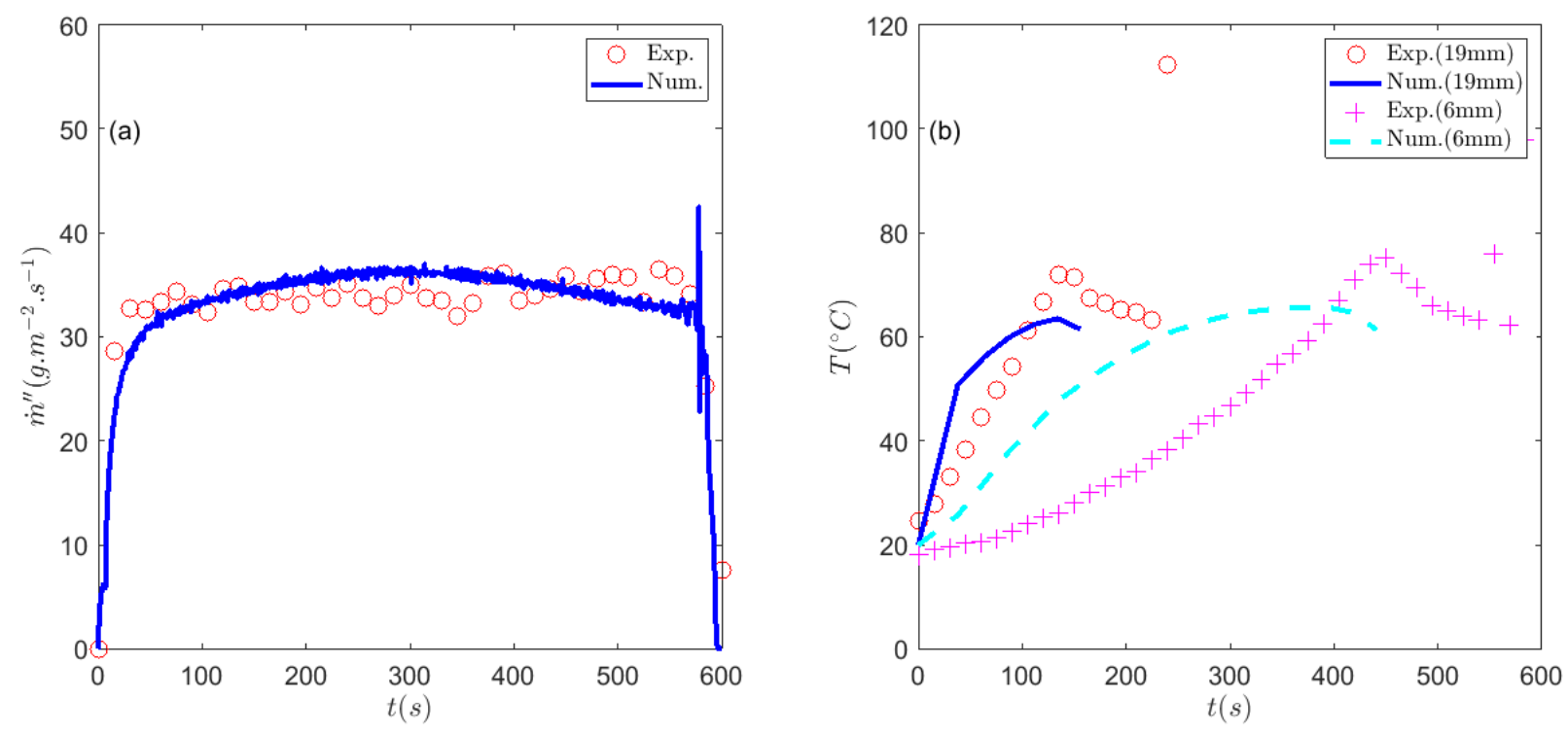

Figure 14 - Experimental and numerical results for the methanol liquid pool at $50 \mathrm{~kW} / \mathrm{m}^{2}$. (a) Transient profiles of MLRPUA. (b) Transient profiles of the liquid temperature at 20 and $6 \mathrm{~mm}$ from the pool bottom.
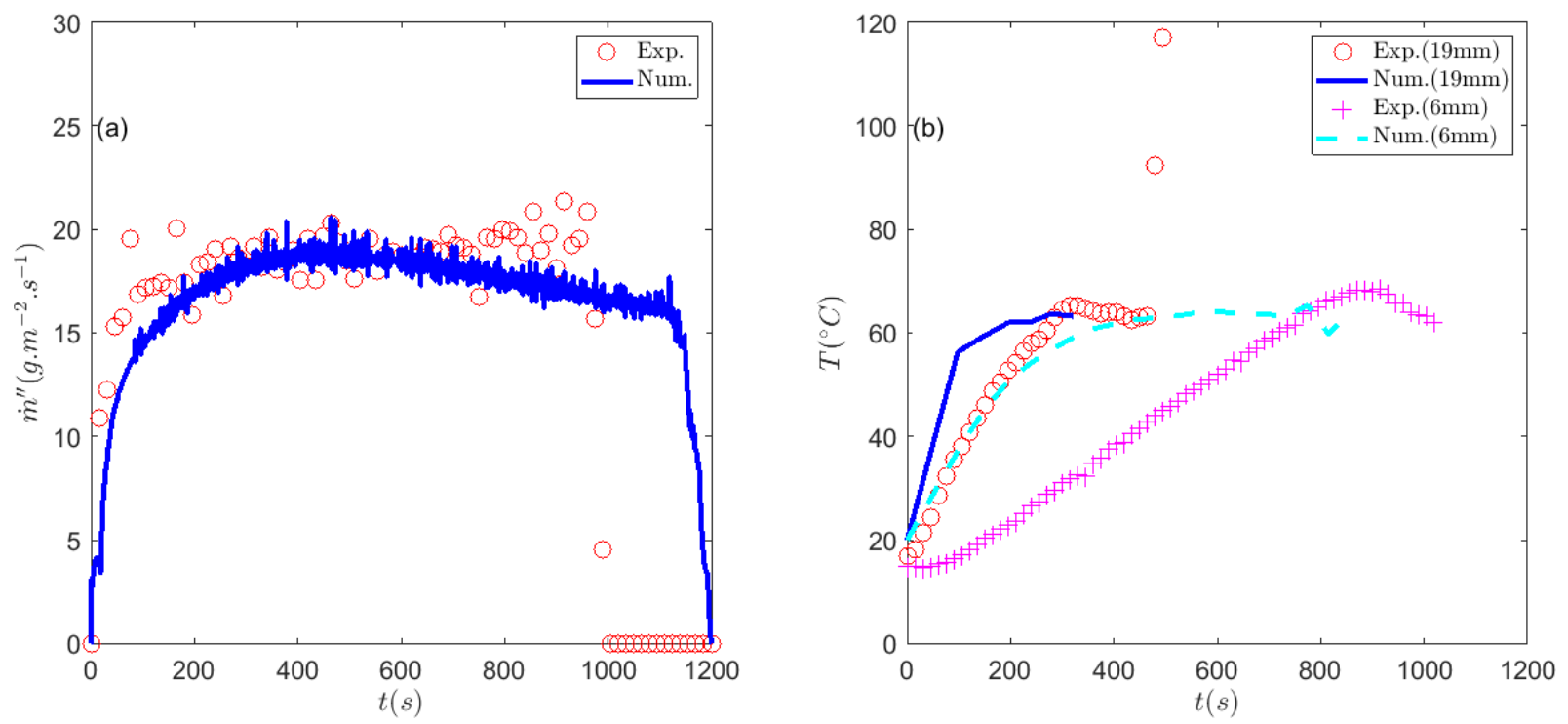

Figure 15 - Experimental and numerical results for the methanol liquid pool at $25 \mathrm{~kW} / \mathrm{m}^{2}$. (a) Transient profiles of MLRPUA. (b) Transient profiles of the liquid temperature at 20 and $6 \mathrm{~mm}$ from the pool bottom. 


\section{Conclusions}

The evaporation rates of methanol and $\mathrm{n}$-heptane have been studied in a Controlled Atmosphere Cone Calorimeter $(\mathrm{CACC})$ in a $0.10 \times 0.10 \times 0.04 \mathrm{~m}^{3}$ steel pan exposed to two 'nominal' irradiation levels of 50 and $25 \mathrm{~kW} / \mathrm{m}^{2}$. The imposed low levels of oxygen allowed to 'inhibit' combustion, the intent being to provide data for model development and validation centered around the heat-up and evaporation processes occurring in liquid pool fires.

CACC (and more generally, cone calorimetry) studies involving liquid fuels are scarce; this experimental methodology is indeed rather used to investigate the thermal decomposition (pyrolysis) behavior of solid fuels such as PMMA and wood. The work presented in this paper is thus, from this perspective, an 'exploratory' work in which we looked into the potential as well as the associated difficulties (points of attention) in using the CACC apparatus as a reliable means of generating high quality dataset that can be of use in the development and validation of models for the prediction of the heat-up and evaporation of liquid pools.

It appeared to be very important to consider the variation of the imposed heat flux, especially in the vertical direction due to the variation in the view factor, as the liquid surface regresses because of evaporation. The latter variation between the start of the test (with an initial fuel height of 25 $\mathrm{mm}$ ) and its end is about $25 \%$ for the tests at hand.

It is also shown that the liquid surface regression leads to an unsteady evaporation process. This is not only due to the variation in the imposed heat flux (mentioned above), but also due to the 'preheating process' that causes an increasing evaporation rate, the extent of which depends on the fuel properties. This phenomenon has been first discussed in the early work of Hayasaka [16] and is further highlighted here for evaporating liquids (without combustion involved).

Estimates of the peak evaporation rates using a 'simple' energy balance are shown not provide a good agreement with the experimentally measured values. The substantial deviations call upon further work to estimate with accuracy the average net heat flux over the liquid surface.

Based on the above, a substantial improvement to the current experimental set-up (and procedure) would be to implement a system where the fuel supply is controlled so that the fuel level remains constant (preferably flush to the top of the pan). Such a system would lead to more 'controllable' conditions with, for instance, no variation in the imposed heat flux. This requires a lot of effort. An easier improvement to put in place is to put more thermocouples in the liquid in order to have a thorough characterization of the thermal structure inside the liquid. 
The numerical study carried out in this work with the Fire Dynamics Simulator (FDS) has shown that an overall good agreement can be achieved by solving the 1D Fourier's equation in conjunction with an evaporation model based on the film theory. Nevertheless, several aspects require 'attention' and further investigation such as (1) the need to increase the thermal conductivity in order to account for convective motion within the liquid, and (2) the need to 'reconsider' the experimental correlation for the calculation of the Sherwood number and examine a 'natural convection' correlation without imposing a minimum Re and thus, a minimum evaporation rate. Furthermore, and in relation with the last point, the results appear to be sensitive to the convection length scale, $L$. Surprisingly, the default value of $L=1 \mathrm{~m}$ provides better results than a more suitable value that is related to the geometry of the problem and which is $L=0.1 \mathrm{~m}$, the side length of the burner.

In a nutshell, we believe that solving the 1D Fourier's equation similarly to thermally thick solids remains an interesting approach (computationally-wise) for the heat-up of liquids in pool fires. Nevertheless, the model for the effective thermal conductivity could be further refined by considering for instance a dynamic approach for the calculation of the internal Nusselt number, $\mathrm{Nu}_{i}$. A similar comment could be made for the liquid absorption coefficient, $\kappa$. Regarding evaporation, it appears that a correlation based on natural convection is worth investigating in the future. We believe that all the above remains of interest to flaming conditions. For the latter case, an additional modelling effort is required at the level of the gas phase (e.g., thermal radiation from the flame, including soot predictions) in order to correctly predict the heat flux at the liquid surface.

\section{Acknowledgements}

The authors foremost acknowledge the financial support and resources provided by the Pprime institute during this project. The authors deeply appreciate the technical support of Mr. Marc Poisson (assistant engineer). This work pertains to the French Government program "Investissements d'Avenir" (LABEX INTERACTIFS, reference ANR-11-LABX-0017-01). We also thank a lot the "Institut des Risques Industriels Assurantiels et Financiers" of the University of Poitiers for its technical support. 


\section{References}

[1] V. Babrauskas, Estimating large pool fire burning rates, Fire Technol. 19 (1983) 251-261. https://doi.org/10.1007/bf02380810.

[2] M.J. Peatross, C.L. Beyler, Ventilation effects on compartment fire characterization, Fire Saf. Sci. 5 (1997), 403-414. https://doi.org/10.3801/iafss.fss.5-403.

[3] A.Y. Snegirev, Statistical modeling of thermal radiation transfer in turbulent buoyant diffusion flames, Combust. Flame 136 (2004) 51-71. https://doi.org/10.1016/j.combustflame.2003.09.005.

[4] S. Suard, M. Forestier. S. Vaux, Toward predictive simulations of pool fires in mechanically ventilated compartments, Fire Saf. J. 61. (2013) 54-64.

https://doi.org/10.1016/j.firesaf.2013.08.010.

[5] T. Beji, B. Merci. Development of a numerical model for liquid pool evaporation, Fire Saf. J. 102 (2018) 48-58. https://doi.org/10.1016/j.firesaf.2018.11.002.

[6] T. Sikanen, S. Hostikka, Modelling and simulation of liquid pool fires with in-depth radiation and heat transfer, Fire Saf. J. 80 (2016) 95-109. https://doi.org/10.1016/j.firesaf.2016.01.002.

[7] I.R. Thomas, K.A.M. Mouinuddin, I.D. Bennetts, The effect of fuel quantity and location on small enclosure fires, J. Fire Protect. Eng. 17 (2007) 85-102.

https://doi.org/10.1177/1042391506064908.

[8] A. Tewarson, Generation of Heat and Chemical Compounds in Fires, in: P.J. DiNenno (Ed.), SFPE Handbook of Fire Protection Engineering, Section 3, Chapter 4, Third Edition, National Fire Protection Association, Quincy, MA, 2002.

[9] T. Beji, B. Merci (2019) Ananlytical Modelling of the Effect of In-Depth Radiation Within a Liquid Layer in the Case of a Pool Fire, $9^{\text {th }}$ International Seminar on Fire and Explosion Hazards, 21-26 April, Saint-Petersburg, Russia. Available at 10.18720/spbpu/2/k19-95.

[10] T. Beji, Theoretical analysis of the liquid thermal structure in a pool fire, Journal of Fire Sciences 39 (2021) 36 - 52. DOI: 10.1177/0734904120962376 
[11] K. McGrattan, S. Hostikka, J. Floyd, R. McDermott, M. Vanella, Fire Dynamics Simulator Technical Reference Guide Volume 1: Mathematical Model. NIST Special Publication 118 - 1 Special Edition. National Institute of Standards and Technology, Gaithersburg, Maryland, US. http://dx.doi.org/10.6028/NIST.SP.1018

[12] V. Babrauskas, W.H. Twilley, M. Janssens, S. Yusa, A Cone Calorimeter for Controlledatmosphere Studies, Fire Mater. 16 (1992) 37-43. https://doi.org/10.1002/fam.810160106.

[13] D. Marquis, E. Guillaume, A. Camillo, Effects of oxygen availability on the combustion behaviour of materials in a controlled atmosphere cone calorimeter, Fire Saf. Sci. 11 (2014), 138-151. https://doi.org/10.3801/iafss.fss.11-138.

[14] D. Marquis, E. Guillaume, D. Lesenechal, Accuracy (trueness and precision) of cone calorimeter tests with and without a vitiated air enclosure, Procedia Eng. 62 (2013) 103-119. https://doi.org/10.1016/j.proeng.2013.08.048.

[15] P. Cremona, Y. Billaud, T. Rogaume, F. Richard, B. Batiot, 2018. Influence of a misalignment of the cone or the sample holder on the view factor with a Monte Carlo approach, Journal of Physics: Conference Series 1107, 032020. https://doi.org/10.1088/17426596/1107/3/032020.

[16] H. Hayasaka, Unsteady Burning Rates of Small Pool Fires, Fire Saf. Sci. (1997) 499-510. https://doi.org/10.3801/iafss.fss.5-499.

[17] A. Vali, D. Nobes, L. W. Kostiuk, Characterization of flow field within the liquid phase of a small pool fire using particle image velocimetry technique, Exp. Thermal Fluid Sci. 75 (2016) 228-234.

[18] A. Vali, D. Nobes, L. W. Kostiuk, Effects of altering the liquid phase boundary conditions of methanol pool fires, Exp. Thermal Fluid Sci. 44 (2013) 786-791.

[19] A. Vali, D. Nobes, L. W. Kostiuk, Fluid motion and energy transfer within burning liquid fuel pools of various thicknesses, Combust. Flame 162 (2015) 1477-1488.

[20] M.T. Wislon, B.Z. Dlugogorski, E. M.Kennedy, Uniformity of radiant heat fluxes in cone calorimeter, Fire Saf. Sci. 7 (2003) 815-827. https://doi.org/10.3801/iafss.fss.7-815. 
[21] A. Hamins, J.C. Yang, T. Kashiwagi, A global model for predicting the burning rates of liquid pool fires, Report No. NISTIR 6383, National Institute of Standards and Technology, Gaithersburg, Maryland, USA, 1999. https://doi.org/10.6028/nist.ir.6381

[22] H. Prétrel (2019) Influence of Pool Size and Fuel Type on the Liquid Fuel Temperature Profile during Burning of Pool Fires in Open Atmosphere, $9^{\text {th }}$ International Seminar on Fire and Explosion Hazards, 21-26 April, Saint-Petersburg, Russia. Available at https://elib.spbstu.ru/dl/2/k19-48.pdf/en/info 